Article

\title{
Preferred Orientation of Quartz in Metamorphic Rocks from the Bergell Alps
}

\author{
Hans-Rudolf Wenk ${ }^{1, *}$, Rong Yu ${ }^{1,2}$, Sven Vogel $^{3}{ }^{(-)}$and Roman Vasin 4 (D) \\ 1 Department of Earth and Planetary Science, University of California, Berkeley, CA 94720, USA; \\ yurong@berkeley.edu \\ 2 School of Urban Planning and Municipal Engineering, Xi'an Polytechnic University, Xi'an 710048, China \\ 3 Material Science \& Technology Division, Los Alamos National Laboratory, Los Alamos, NM 87545, USA; \\ sven@lanl.gov \\ 4 Joint Institute for Nuclear Research, 141980 Dubna, Russia; olddragon@mail.ru \\ * Correspondence: wenk@berkeley.edu
}

Received: 7 March 2019; Accepted: 1 May 2019; Published: 5 May 2019

check for updates

\begin{abstract}
Crystal preferred orientation of 47 samples of quartzite and eight samples of associated marbles from the Bergell Alps have been analyzed with time-of-flight neutron diffraction and EBSD. The results show a clear distinction of texture types for quartzites transformed from Triassic sandstones and quartz layers in gneiss. Textures of Triassic quartzites are overall weak and display a maximum of c-axes perpendicular to the foliation or a crossed girdle perpendicular to the lineation. Pole figures for positive rhombs $\{10 \overline{1} 1\}$ show a maximum perpendicular to the foliation and negative rhombs $\{01 \overline{1} 1\}$ generally display a minimum. Based on polycrystal plasticity models this texture type can be attributed to a combination of basal and rhombohedral slip. Asymmetry of the distributions is attributed to simple shear and local strain heterogeneities. The relatively weak texture is partially caused by muscovite limiting dislocation motion and grain growth, as well as adjacent layers of marble that accommodate significant strain. Most quartz layers in gneiss, including mylonites, display a texture with a-axes parallel to the lineation and a c-axis maximum in the intermediate fabric direction. This texture type can be attributed to dominant prismatic slip. Many samples are recrystallized and recrystallization appears to strengthen the deformation texture. The study shows good agreement of neutron diffraction and EBSD. Neutron diffraction data average over larger volumes and maximum pole densities are generally lower and more representative for the bulk material. With EBSD the microstructure and mechanical twinning can be quantified.
\end{abstract}

Keywords: quartzite; preferred crystal orientation/texture; neutron diffraction; EBSD; Central Alps

\section{Introduction}

Preferred orientation in quartzites has been of interest for a long time, beginning with the first fabric diagram by Schmidt (1925) [1] and extensive reviews by Sander (1950) [2]. Quartz is one of the dominant minerals in metamorphic rocks of the Earth's crust, and fabric patterns have been used to understand tectonic deformation in many regions such as Saxony granulites [3-6], Moine thrust mylonites [7-9], mylonites in Central Australia [10], quartzites in Alpine nappes [11-14], and recently, the Himalayan belt [15-18]. These investigations documented a wide range of quartz fabric types with variations attributed to metamorphic grade, deformation mechanisms, and the strain history.

Early studies relied on optical measurements of quartz c-axes with a Universal stage and a petrographic microscope. For trigonal quartz optical methods can only be used to determine c-axes. In 1967, X-ray pole figure measurements were applied to quartz, opening the possibility to obtain crystal orientations for other lattice directions than c-axes [19]. This was used to quantify the 
development of mechanical twins in flint deformed in axial compression [20]. From a set of pole figures the full orientation distribution function (ODF) for trigonal quartz was obtained with the harmonic method [21,22]. With advances in electron backscatter diffraction (EBSD) in scanning electron microscopes, quartz crystal orientations could be determined in small volumes and represented as two-dimensional maps [23], similar to the "Achsenverteilungsanalyse" (AVA) of Sander [2] but including full crystal orientations. An early application to quartz is the study of Kunze et al. [24]. Another comparably novel tool-neutron diffraction-became available to determine full orientation distributions on large samples, with much better grain statistics than optical measurements or EBSD [25].

The new measurement techniques rely on sophisticated data analysis, which was first developed for cubic metals. It became apparent that the harmonic method mentioned above, and introduced by Bunge [26] and Roe [27], had limitations because of the omission of odd coefficients in ODF calculations [28] and new methods were developed such as WIMV [29], ADC [30], and the maximum entropy method [31,32]. Generalizing analytical methods to include lower than cubic crystal symmetries introduces some complications.

While many deformation experiments on single crystals to determine deformation mechanisms have been performed on minerals such as calcite, dolomite and olivine, there is much less information on quartz [33,34]. The study of Baeta and Ashbee (1970) [35] is still a landmark. Slip systems have been identified by TEM observations of dislocations in deformed quartzites, or inferred from texture patterns by comparison with polycrystal plasticity models.

Before going into details, let us clarify a few terms used in this paper. To describe the anisotropic pattern of crystals in deformed rocks d'Omalius d'Halloy [36] introduced the term "texture" in his 1833 textbook. Later this was applied more generally to what is known as microstructure. Schmidt [1] and Sander [2] introduced the term "fabric" (Gefüge), which is widely used in structural geology to describe preferred orientation. In materials science "texture" has become synonymous with crystal preferred orientation (or $\mathrm{CPO}$ ) and we use all three expressions in this paper since materials science and geology have become closely connected.

Here we study bulk textures in 47 samples of quartzites from different geologic environments of the Bergell region in the Swiss Alps. As will become apparent, texture patterns are more complex than anticipated, yet some significant trends were observed. Most studies of preferred orientation in quartz have focused on a few selected samples. In order to address the regional significance and extent of local variations of quartz textures it was important to investigate many samples. With such an approach it was possible to unravel features that were in many ways unexpected. Therefore, we present not only a large number of samples, but also for each sample several pole figures, not just c-axes and a-axes of quartz.

The microstructure of samples was first studied by optical microscopy. Preferred orientation was measured with neutron diffraction over many years. Selected samples were also investigated with EBSD to explore the role of mechanical Dauphiné twinning from orientation maps. In the discussion we will try to model observed texture patterns with polycrystal plasticity theory and considerations of dynamic recrystallization under stress. An important factor that was emerging is the significance of rhombohedral orientations, which cannot be inferred from simple c-axis pole figures.

\section{Samples}

The samples were collected in the Bergell Alps (Southern Switzerland and Northern Italy), which is a region of the southeastern Alps extending from the Lake of Como (SW) to the Engadine (NE). Figure 1 shows the tectonic units with a sequence of Pennine nappes (Adula, Tambo, Suretta, Avers, and Platta) overlain by lower Austrolapine nappes (Margna and Bernina) in the East [37-39]. These nappes display a crystalline basement covered by metasedimentary layers. Most pronounced are Triassic quartzites and marbles transformed from sandstones and limestones. Into this stack of nappes there was an intrusion of Bergell granite in the South in the Tertiary ( $\sim 30 \mathrm{My}$.), causing considerable temperature gradients, with metamorphic grade ranging from granulite to greenschist facies. 


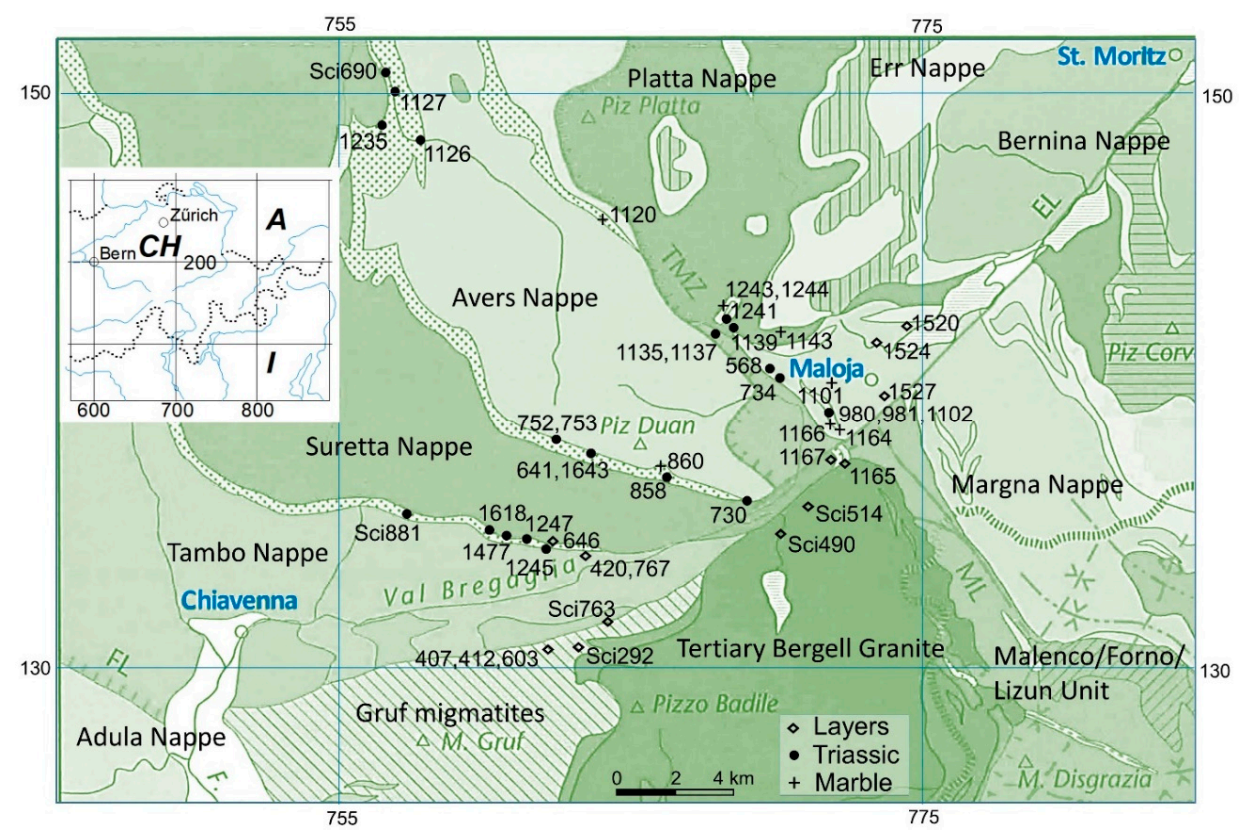

Figure 1. Tectonic map of the Bergell Alps based on Montrasio et al. [39]. Dotted zones are Triassic metasediments where quartzites and marbles were collected. Sample locations are indicated. If only numbers are given they refer to Brg (Table 1). EL: Engadine Line; ML: Muretto Line; TMZ: Turba Mylonite Zone; FL: Forcola Line. The coordinate system used in Swiss topographic maps is indicated. In the insert an overview is shown with countries ( $\mathrm{CH}$ : Switzerland; I: Italy; A: Austria).

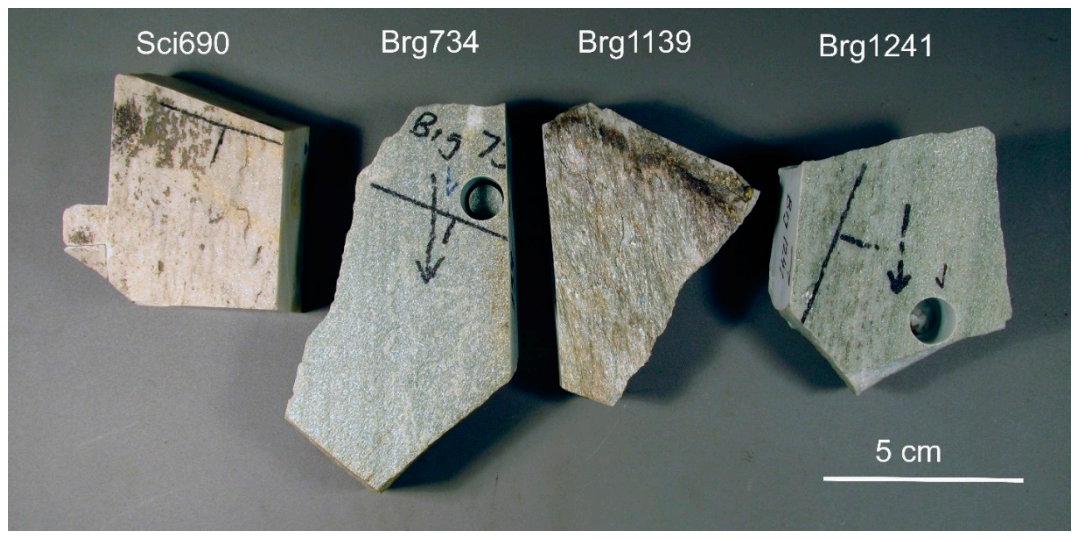

Figure 2. Four typical hand specimens of Triassic quartzites. They display an excellent foliation and the lineation on the schistosity plane. Scale is indicated. In samples Brg734 and Brg1241 there is a cylindrical hole from which the neutron diffraction samples were obtained.

In conjunction with a tectonic study of this area [40] and an exploration of the metamorphic history [41], samples of quartzite and some associated marbles were collected. Of these 39 quartzites, eight marbles are displayed and discussed in some detail in the main text. Information about another eight quartzite samples is provided in Supplementary Material. Quartzite samples can be divided into Triassic quartzites (referred to as " $\mathrm{T}$ ") transforming during the Tertiary Alpine metamorphism from sandstones, and quartz layers in crystalline basement ("L"). Sample localities are shown in the tectonic map (Figure 1) and are listed in Table 1 with Swiss coordinates (130-150 km SN and 755-775 $\mathrm{km}$ WE). In Table 1 samples in each group are sorted according to sample numbers (first Brg, then Sci). This same order will be used for microstructures and pole figures. Some hand specimens of Triassic quartzites are shown in Figure 2. They display an excellent foliation and a well-developed lineation, with strong alignment of muscovite platelets. Foliation and lineation were used to define a sample coordinate system to represent crystal preferred orientation. 
Table 1. List of samples with location, Swiss coordinates (in $\mathrm{km}$ ) and (0001) pole figure maxima (in multiples of a random distribution) as well as texture index J for neutron and EBSD textures. The $x$ after sample number indicates that optical microstructure is displayed in Figures 3 and 4; D indicates Dubna data. + in the electron backscatter diffraction (EBSD) column indicates that map is displayed in Figure 11, and * that comparison of neutron and EBSD pole figures is shown in Figure 12. Additional samples are listed in Table S1.

\begin{tabular}{|c|c|c|c|c|c|c|}
\hline \multirow{2}{*}{ Sample \# } & \multirow{2}{*}{ Place } & \multirow{2}{*}{ Coord. } & \multicolumn{2}{|c|}{ Neutron } & \multicolumn{2}{|c|}{ EBSD } \\
\hline & & & 0001 & $\mathbf{J}$ & 0001 & $\mathbf{J}$ \\
\hline \multicolumn{7}{|c|}{ A: 24 Triassic quartzites } \\
\hline $\operatorname{Brg} 568 x$ & Alpascela & $770.1 / 141.5$ & 12.4 & 5.5 & $15.5+*$ & 10.3 \\
\hline Brg $641 x$ & Val Duana & $763.3 / 139.6$ & 2.4 & 1.2 & $6.6+$ & 4.0 \\
\hline Brg 730 & Roticcio & $769.0 / 136.85$ & 4.2 & 1.8 & & \\
\hline Brg 734 & Alpascela & 770.1/141.1 & 8.5 & 3.6 & & \\
\hline Brg 752 & Bergalga & $762.95 / 139.25$ & 2.7 & 1.4 & & \\
\hline Brg 753 & Bergalga & $762.95 / 139.25$ & 2.0 & 1.2 & & \\
\hline Brg $858 x$ & Cam & $766.35 / 137.55$ & 5.4 & 1.8 & & \\
\hline Brg $980 x$ & Casaccia & $771.8 / 139.7$ & 5.4 & 2.0 & $9.0 *$ & 8.2 \\
\hline Brg $981 x$ & Casaccia & $771.8 / 139.6$ & 7.1 & 3.2 & $9.3+$ & 5.3 \\
\hline Brg 1102 & Casaccia & $771.8 / 139.65$ & 6.9 & 3.2 & & \\
\hline Brg 1126 & Avers Croet & $757.3 / 149.4$ & 3.6 & 2.1 & $7.5+*$ & 5.2 \\
\hline $\operatorname{Brg} 1127 x$ & Campsut & $756.1 / 151.5$ & 3.4 & 1.9 & $5.0+$ & 4.1 \\
\hline Brg 1135 & Septimer & $767.6 / 142.7$ & 2.3 & 1.2 & $5.2 *$ & 3.5 \\
\hline Brg 1137 & Val Turba & $768.1 / 142.6$ & 3.9 & 1.9 & $7.1+$ & 4.2 \\
\hline Brg $1139 x$ & Septimer & $768.5 / 142.7$ & 3.7 & 1.9 & & \\
\hline $\operatorname{Brg} 1235 \mathrm{x}$ & Lago di Lei & $755.9 / 155.5$ & 5.1 & 1.8 & & \\
\hline Brg 1241 & Val Turba & 768.1/143.1 & 8.8 & 4.4 & & \\
\hline $\operatorname{Brg} 1245 x$ & Plan Vaest & $762.1 / 135.15$ & 4.0 & 2.2 & & \\
\hline Brg 1247 & Plan Vaest & $762.1 / 135.1$ & 2.9 & 1.5 & & \\
\hline Brg 1477 & Bugna & $760.9 / 135.45$ & 2.9 & 1.0 & $3.6+$ & 1.9 \\
\hline Brg 1618D x & Cavi & $760.1 / 135.7$ & 2.3 & 1.5 & $6.6+$ & 3.2 \\
\hline Brg 1643D & Duana & $764.35 / 139.2$ & 6.4 & 2.7 & $11.3+$ & 5.5 \\
\hline Sci $690 x$ & Innerferrera & $756.0 / 152.1$ & 5.8 & 2.7 & $8.4+$ & 5.1 \\
\hline Sci $881 x$ & Pso. Turbine & $757.0 / 136.0$ & 3.9 & 1.8 & $3.9+*$ & 6.4 \\
\hline \multicolumn{7}{|c|}{ B: 15 Quartz layers } \\
\hline Brg 407 & Tegiola & $762.5 / 130.1$ & & & $21.1+$ & 14.5 \\
\hline $\operatorname{Brg} 412 x$ & Tegiola & $762.6 / 130.05$ & 12.9 & 4.5 & & \\
\hline Brg $420 x$ & Caccior & $763.4 / 134.9$ & 15.0 & 9.8 & & \\
\hline Brg $603 x$ & Tegiola & $762.2 / 130.25$ & 16.9 & 11.9 & $19.6+*$ & 22.1 \\
\hline $\operatorname{Brg} 646 x$ & Tombal & $762.3 / 135.3$ & 7.5 & 4.6 & & \\
\hline Brg 767 & Caccior & $763.4 / 135.1$ & 6.1 & 2.5 & & \\
\hline Brg 1165 & Lavinair Crusc & $772.55 / 138.25$ & 2.2 & 1.2 & & \\
\hline Brg 1167 & Lavinair Crusc & $771.85 / 138.25$ & 4.9 & 1.7 & $9.3^{*}$ & 6.6 \\
\hline Brg $1520 x$ & Blaunca & $774.5 / 142.8$ & 12.4 & 5.3 & $21.3+$ & 22.1 \\
\hline Brg $1524 x$ & Plan di Zoch & $773.75 / 142.7$ & 8.8 & 4.4 & $11.8+$ & 8.5 \\
\hline Brg 1527 & Orden & $773.6 / 140.5$ & 9.4 & 6.0 & & \\
\hline Sci 292 x & Tegiola & $763.4 / 130.3$ & 29.2 & 18.4 & $36.4^{*}$ & 26.9 \\
\hline Sci $490 \mathrm{x}$ & Albigna & $770.5 / 136.3$ & 4.7 & 2.2 & & \\
\hline Sci $514 x$ & V. Largh & $771.2 / 136.7$ & 4.3 & 1.7 & & \\
\hline Sci 763 & Lera d'Sura & $762.6 / 132.0$ & 26.3 & 11.5 & $51.7+$ & 74.1 \\
\hline \multicolumn{7}{|c|}{ C: 8 Marbles (do is dolomite) } \\
\hline Brg860 & Pass dal Cam & $766.3 / 137.55$ & 2.1 & 1.1 & & \\
\hline Brg1101 & Casaccia (do) & $771.7 / 140.0$ & 1.6 & 1.1 & & \\
\hline Brg1120 & Juf & $764.37 / 146.3$ & 3.4 & 1.3 & & \\
\hline Brg1143 & Alpascela & 769.7/141.4 & 2.2 & 1.2 & & \\
\hline Brg1164 & Lavinair Crusc & $772.55 / 138.2$ & 2.2 & 1.2 & & \\
\hline Brg1166 & Lavinair Crusc & $771.85 / 138.2$ & 3.7 & 1.7 & & \\
\hline Brg1243 & Val Turba & $768.3 / 142.8$ & 2.1 & 1.2 & & \\
\hline Brg1244 & Val Turba & $768.3 / 142.8$ & 3.1 & 1.4 & & \\
\hline
\end{tabular}


While hand specimens look rather similar, there is a wide range of microstructures as illustrated in micrographs of thin sections (Figure 3 for some of the Triassic quartzites and Figure 4 for quartz layers, see also Figures S1 and S2 for a more complete survey). The thin sections were obtained by cutting slabs perpendicular to the foliation and parallel to the lineation. The microstructure images are obtained with crossed polarizers and by inserting a "gypsum plate" to document for many samples a wide range of crystal orientations (different colors). Figures S1 and S2 show microstructures of all samples without gypsum plate and simply crossed polars.
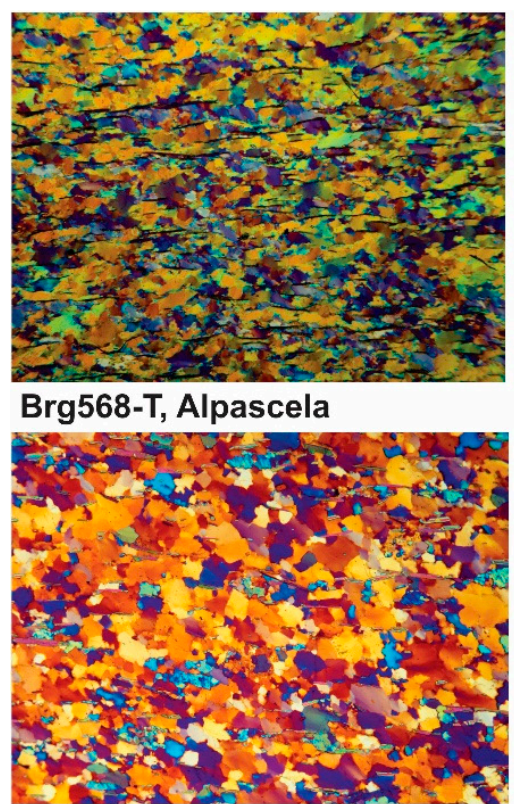

Brg980-T, Casaccia

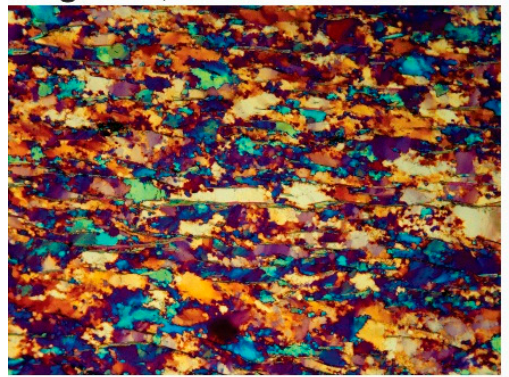

\section{Brg1139-T, Septimer}

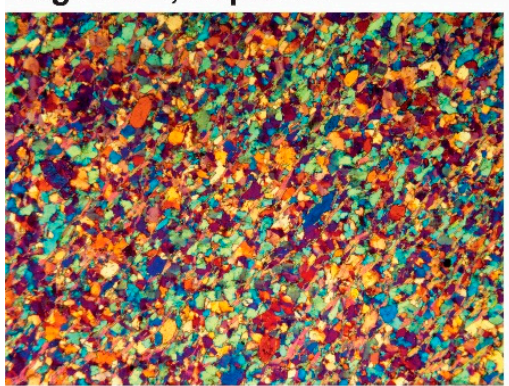

Brg1618-T, Cavi
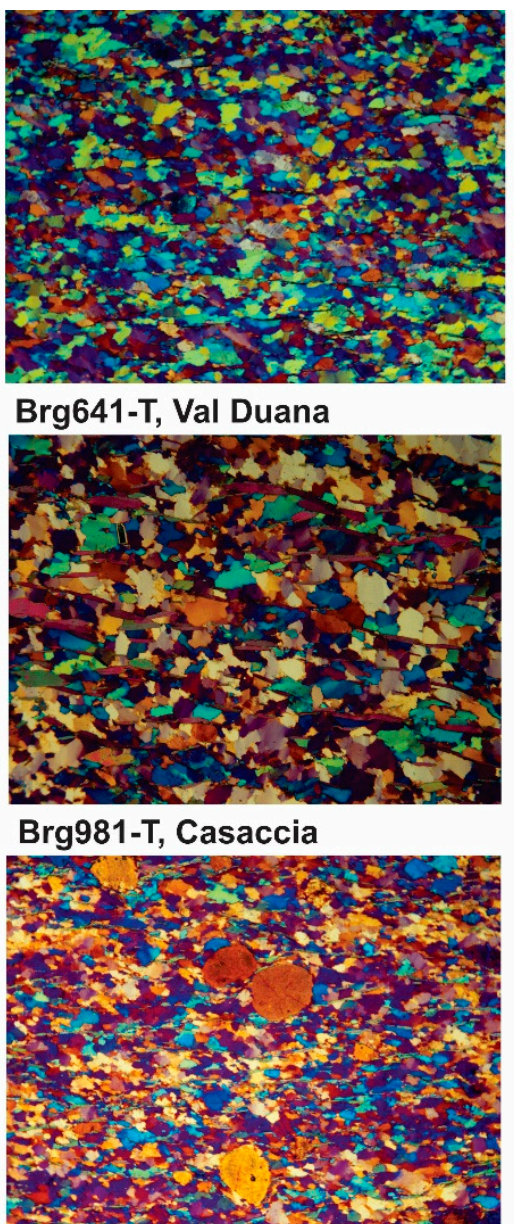

Brg1235-T, Lago di Lei

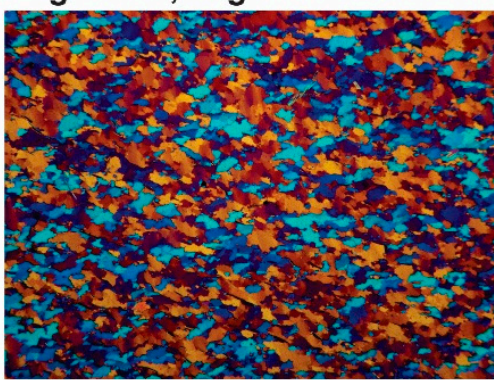

Sci690-T, Innerferrera

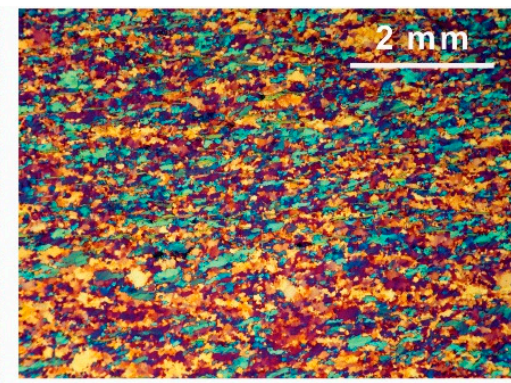

Brg858-T, Cam

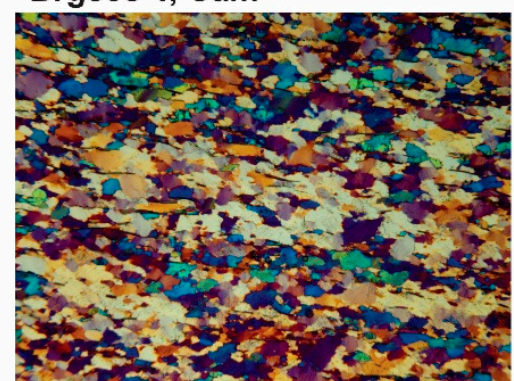

Brg1127-T, Campsut

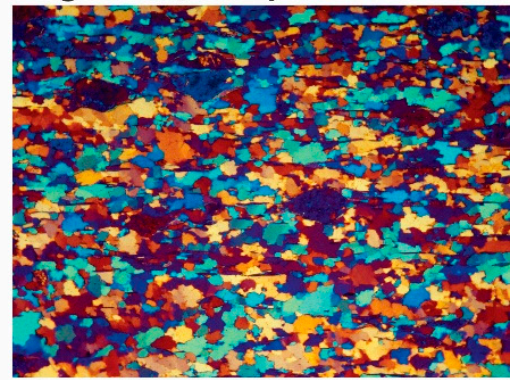

Brg1245-T, Plan Vaest

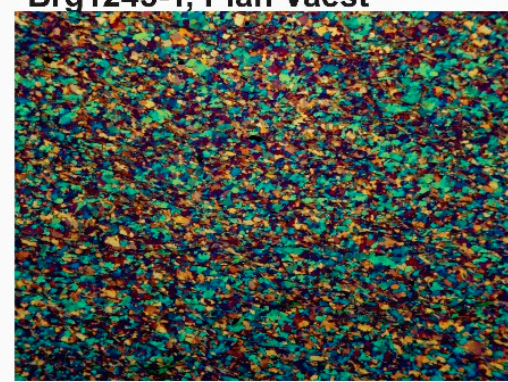

Sci881-T, Pso. Turbine

Figure 3. Optical images of thin sections from selected Triassic quartzites. Crossed polarizers, gypsum plate inserted to highlight orientation differences. Scale indicated at top right. For more images with crossed polarizers only see Supplementary Material Figure S1. Order of samples is the same as in Table 1. 
Grain size varies from 0.05 to $1 \mathrm{~mm}$ for Triassic quartzites (Figure 3) and 0.05 to $4 \mathrm{~mm}$ for quartz layers (Figure 4). Grain shapes range from equiaxed (e.g., Brg980 and Brg1524) to highly flattened for mylonitic layers in the vicinity of the granite contact (e.g., Brg603, Sci490, and Sci514), and also for some Triassic quartzites (e.g., Brg858, Brg1245, and Brg1643). Only a few microstructural images display uniform colors (e.g., Brg412, Brg420, Brg646, and Sci292), indicative of simple c-axis orientation patterns, while most show a wide range of colors, suggesting more complex textures.

Some higher magnification images without gypsum plate are shown in Figure 5. In many Triassic quartzites quartz contains deformation lamellae (e.g., Brg1127 and Brg1618). Muscovite platelets are generally strongly aligned, bordering quartz grains (Brg1137 and Brg1139), or quartz including platelets (Brg1241). In many samples there is evidence of grain growth during dynamic recrystallization. In mylonitic quartzites we observe a fine-grained quartz matrix flowing plastically around more rigid feldspar inclusions (e.g., Brg412 and Sci292).

The samples described here are available for researchers who want to follow up on our studies to obtain additional information.

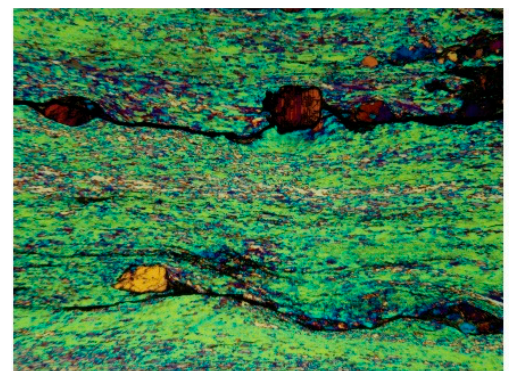

Brg412-L, Tegiola

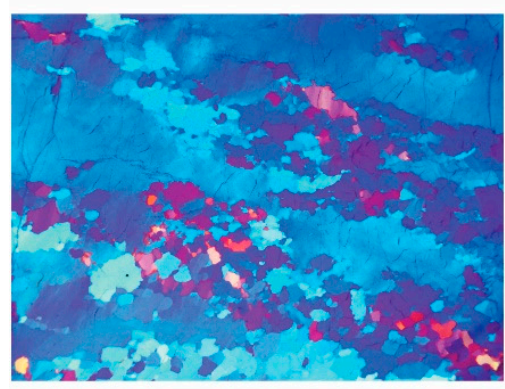

Brg646-L, Tombal

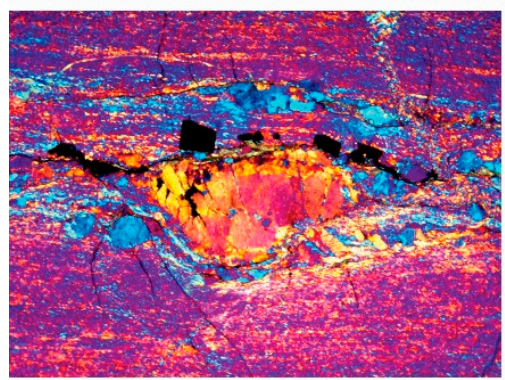

Sci292-L, Tegiola

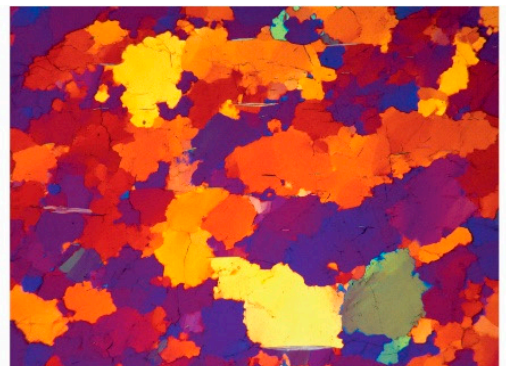

Brg420-L, Caccior

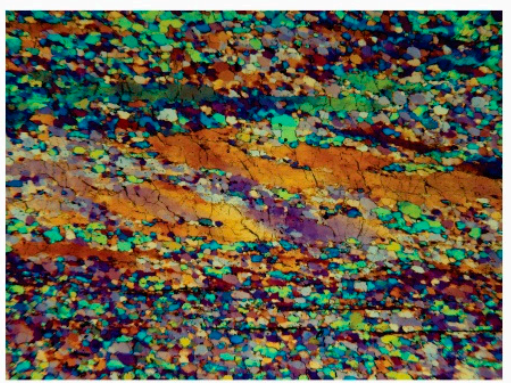

Brg1520-L, Blaunca

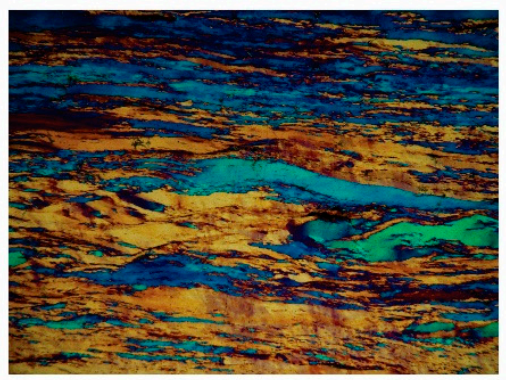

Sci490-L, Albigna

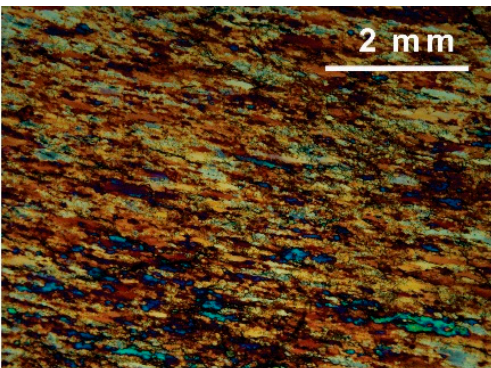

Brg603-L, Tegiola

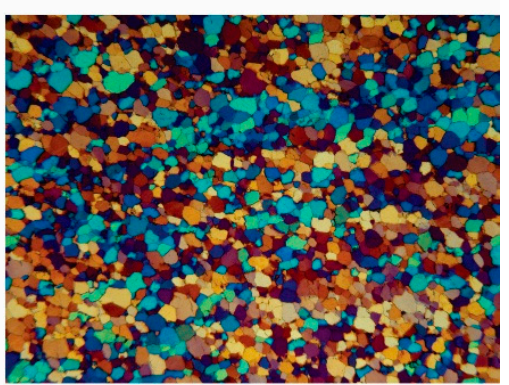

Brg1524-L, Plan di Zoch

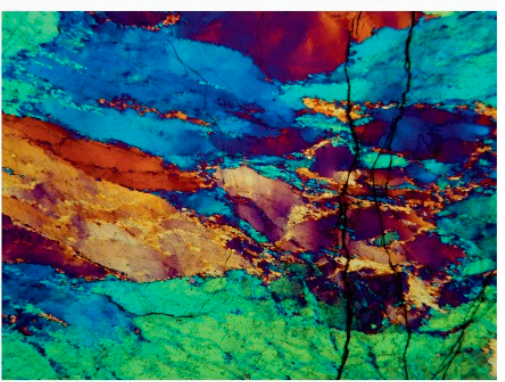

Sci514-L, V. Largh

Figure 4. Optical images of thin sections from selected quartz layers. Crossed polarizers, gypsum plate inserted to highlight orientation differences. Scale indicated at top right. For more images with crossed polarizers only see Supplementary Material Figure S2. Order of samples is the same as in Table 1. The large clasts in Brg412 and Sci292 are feldspar. 


\section{Triassic quartzites}

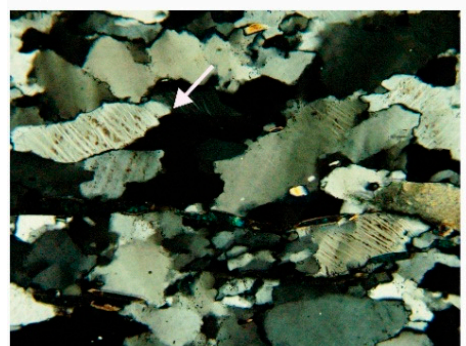

Brg1127, Campsut

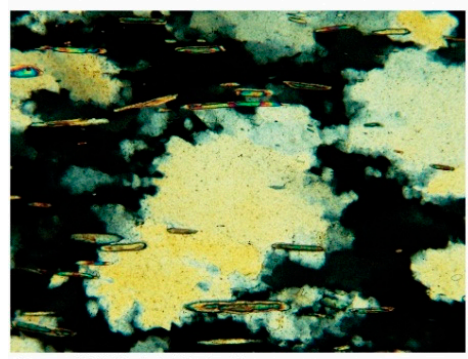

Brg1241, Val Turba

Quartz layers

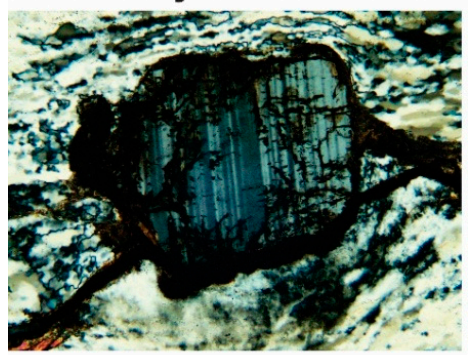

Brg412, Tegiola

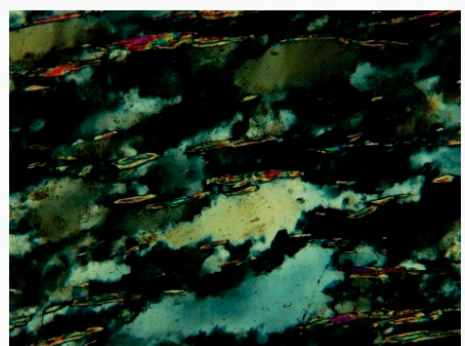

Brg1137, Val Turba

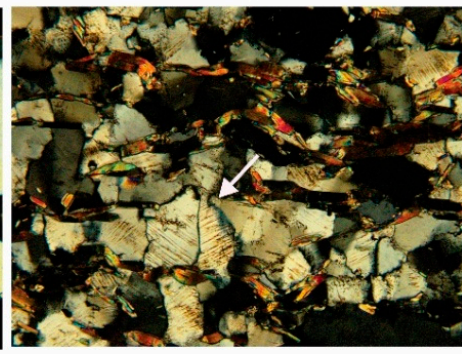

Brg1618, Cavi

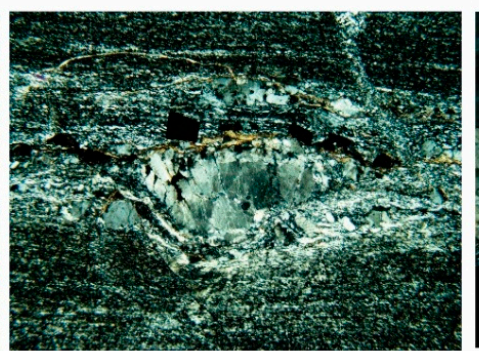

Sci292, Tegiola

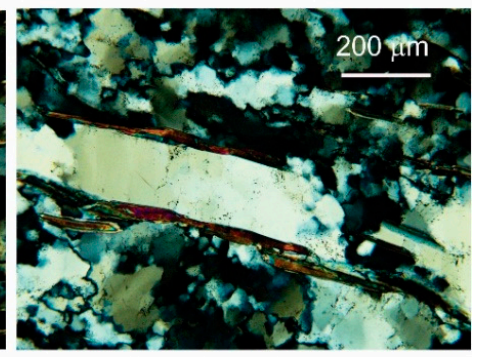

Brg1139, Septimer

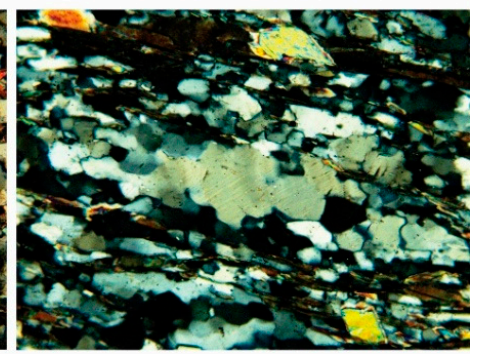

Sci881, Pso. Turbine

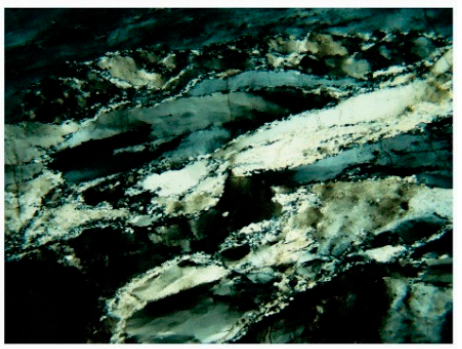

Sci514, Vallun Largh

Figure 5. Optical images of selected samples at high magnification. Crossed polarizers. Scale indicated at top right. Clasts in Brg412 and Sci292 are plagioclase, colored phases are muscovite. White arrows in Brg1127 and Brg1618 point to well visible deformation lamellae.

\section{Experimental Methods}

\subsection{Some Remarks on Coordinate Systems and Quartz Crystallography}

Most ODF calculations relate a Cartesian right-handed sample coordinate system XYZ to a Cartesian right-handed crystal coordinate system $X_{C} Y_{C} Z_{C}$ with three rotations defined by Euler angles.

In accordance with, e.g., the review of Law (1990) [42], the sample coordinate system XYZ is defined by

$\mathrm{Z} \|$ pole to the folation $s, \quad \mathrm{X} \|$ lineation $l, \quad \mathrm{Y} \| \mathrm{Z} \times \mathrm{X}$

Quartz, in most tectonic environments, has trigonal symmetry and is referred to as alpha quartz. The complication is that quartz can exist in a right-handed and left-handed form [43,44]. According to an extensive comparative study of a large number of quartz single crystals by Frondel [45], both enantiomorphic modifications are equally abundant in nature, though local dominance of one enantiomorph may occur. Enantiomorphs cannot be resolved with diffraction techniques unless an exeptional experimental setup is used [46], and have not been taken into account in quartz fabric studies. Consequently, we attributed all investigated quartz to the right-handed spacegroup $\mathrm{P}_{1} 21$ (\#152) while the left-handed spacegroup is $\mathrm{P}_{2} 21$ (\#154). 
How do we define an orthogonal crystal coordinate system in trigonal quartz? Here we follow the definition of Matthies et al. [47], which defines the orthogonal crystal coordinate system $X_{C} Y_{C} Z_{C}$ relative to trigonal lattice vectors $A_{1}=a=[2 \overline{11} 0], A_{3}=c=[0001]$ as

$\mathrm{Z}_{\mathrm{C}}\left\|\mathrm{A}_{3}, \quad \mathrm{Y}_{\mathrm{C}}\right\| \mathrm{A}_{3} \times \mathrm{A}_{1}, \quad \mathrm{X}_{\mathrm{C}}\left\|\mathrm{Y}_{\mathrm{C}} \times \mathrm{Z}_{\mathrm{C}}\right\| \mathrm{A}_{1}$.

Note that in the literature different conventions are sometimes used for defining $X_{C}$ and $Y_{C}$.

Another complication for the texture analysis is that for trigonal quartz, pairs of rhombohedral reflections such as $10 \overline{1} 1$ and $01 \overline{1} 1,10 \overline{1} 2$ and $01 \overline{1} 2$, or $20 \overline{2} 1$ and $02 \overline{2} 1$ have the same lattice spacings and are completely overlapped in diffraction patterns. These reflections are crucial for the determination of the trigonal quartz texture. The pole figure deconvolution is based on different diffraction intensities due to different structure factors of neutrons or electrons scattered from corresponding crystal lattice planes [48].

All pole figures (i.e., Figures 7-10) are plotted as equal area projections on the schistosity plane XY with the $\mathrm{X}$ axis NS (lineation $l$ on top). This geometry is different from most studies of quartz preferred orientation. It is chosen because it provides least distortion of (0001) pole figures, and particularly in the distinction of positive rhombs $\{10 \overline{1} 1\}$ and negative rhombs $\{01 \overline{1} 1\}$ relative to the normal to the schistosity.

Pole figures express pole densities in multiples of a uniform distribution (mrd). The texture strength or sharpness of the ODF of the polycrystalline aggregate can be described with the texture index $\mathrm{J}=\mathrm{f}^{2}$ as defined by Matthies et al., 1988 (their Equation (38)) [47]:

$$
J=f^{2} \equiv \int_{G} f^{2}(g) d g / 8 \pi^{2}
$$

integrating squared ODF values $\mathrm{f}^{2}(\mathrm{~g})$ over the orientation space $G$.

\subsection{Neutron Diffraction}

Crystallographic preferred orientation was measured by time-of-flight neutron diffraction. Since neutrons have relatively low attenuation by most elements (or isotopes to be more accurate), large samples can be analyzed, providing excellent grain statistics compared to more conventional methods such as optical measurements with a universal stage petrographic microscope, electron backscatter diffraction (EBSD) with a scanning electron microscope, or classical X-ray diffraction with a pole figure goniometer. Some general aspects of neutron texture measurements will be discussed in Section 5.8.

Most samples were measured with the HIPPO (High Pressure Preferred Orientation) neutron time-of-flight (TOF) diffractometer at the accelerator-based neutron facility LANSCE, Los Alamos National Laboratory [49]. The unique features of HIPPO are high neutron flux (owing to its comparably short moderator-to-sample distance of $8.8 \mathrm{~m}$ ) and a large array of detectors arranged in several rings around the neutron beam direction. Cylindrical samples, $1 \mathrm{~cm}$ in diameter and $1 \mathrm{~cm}$ long, were mounted on a rod and entered in a sample changer (Figure $6 \mathrm{c}$ ). A collimated beam of thermal neutrons (wavelengths $\sim 0.2-6 \AA$ ), $1 \mathrm{~cm}$ in diameter, enters the HIPPO diffractometer and diffraction occurs on the sample. The signal is recorded as TOF spectra by 30 detector panels, consisting of ${ }^{3} \mathrm{He}$ detector tubes, on $2 \theta=40^{\circ}(19-30), 90^{\circ}(9-18)$ and $150^{\circ}(1-8)$ banks. Figure 6a shows the pole figure coverage by projecting the 30 detectors on a pole figure with the sample cylinder axis in the center. It illustrates that the angular coverage varies considerably between the detector panels $\left(5-20^{\circ}\right)$. The pole figure coverage is improved by rotating the sample in four increments about the vertical axis $\left(0^{\circ}, 45^{\circ}, 67.5^{\circ}\right.$, and $90^{\circ}$ ), resulting in $4 \times 30=120$ spectra (Figure $6 \mathrm{~b}$ ). TOF diffraction spectra were recorded for a preset beam monitor count, resulting in approximately $40 \mathrm{~min}$. Note that in the 15 -year period over which these samples were measured, some details of detectors and coverage scheme have changed. This has been taken into account in data processing and is therefore not described in detail. 
Figure $6 \mathrm{~d}$ illustrates a sum of neutron diffraction spectra collected by the $2 \theta=90^{\circ}$ and $40^{\circ}$ detectors for Brg981 quartzite. Some diffraction peaks are indexed. The high angle detector (top) has a much better resolution than the low angle detector (bottom), but the low-angle detector has a much better pole figure coverage and counting statistics (Figure 6a). Figure 6e displays a stack of individual spectra for the $40^{\circ}$ detector bank (bottom are measured spectra) with variations in azimuth expressed from bottom to top. Intensity variations as a function of azimuth are indicative of crystal preferred orientation.
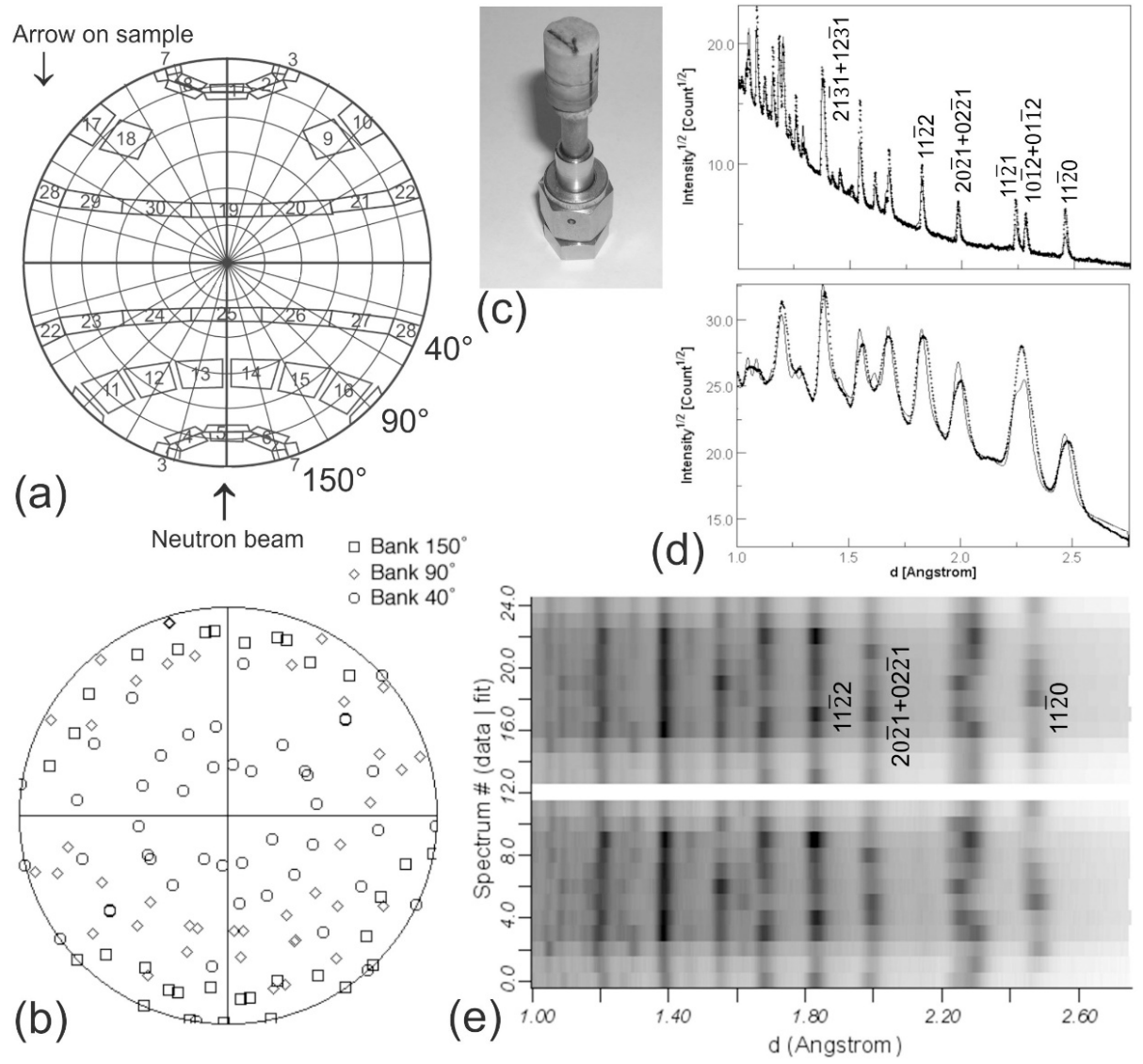

Figure 6. Neutron diffraction texture measurements with HIPPO. (a) shows the pole figure coverage using 3 detector banks $\left(40^{\circ}, 90^{\circ}\right.$, and $\left.150^{\circ}\right)$. The approximate area covered by a single detector is shown on the pole figure in equal area projection. (b) Coverage with 4 sample rotations around the vertical axis $\left(0^{\circ}, 45^{\circ}, 67.5^{\circ}\right.$, and $\left.90^{\circ}\right)$. (c) View of a cylindrical quartzite sample. The diameter of the cylinder is $1 \mathrm{~cm}$. (d) Diffraction spectrum for the $40^{\circ}$ and $90^{\circ}$ detector banks (dots) and the corresponding Rietveld fit (line). Some diffraction peaks of quartz are indexed. (e) Stack of diffraction spectra for one rotation for the $40^{\circ}$ detector. Bottom are the experimental data and top is the Rietveld fit. Intensity variations correspond to crystal preferred orientation.

Samples Brg1618 and Brg1643 were measured on the TOF neutron diffractometer SKAT at beamline 7A2 of the IBR-2 pulsed reactor at the Joint Institute for Nuclear Research (JINR), Dubna, Russia [50,51]. SKAT is characterized by a large beam cross section, allowing measurements of samples of $\sim 100 \mathrm{~cm}^{3}$ volume, and both samples were spheres of $5 \mathrm{~cm}$ diameter, resulting in excellent grain statistics. The standard setup of the diffractometer, including $19{ }^{3}$ He detectors with $45^{\prime}$ Soller collimators at the same scattering angle $2 \theta=90^{\circ}$, has been used. The combined thermal and cold moderator for the beamline 7A2 was in operation and this improved neutron counts. During measurements samples were rotated in $15^{\circ}$ increments, and 24 sample positions were measured to obtain complete experimental pole figures, resulting in $24 \times 19=456$ neutron diffraction spectra. Measurement time at each sample position was $1.5 \mathrm{~h}$ ( $36 \mathrm{~h}$ total). 
The 120 neutron TOF diffraction spectra from HIPPO and 456 spectra from SKAT were then analyzed with the Rietveld method as implemented in MAUD [52] and described in a tutorial for neutron time-of-flight texture analysis [25]. The refinements rely on the crystal structure of low quartz [53]. In the Rietveld procedure instrumental parameters, background, crystallographic parameters, coherent scattering domain sizes and r.m.s. microstrains, phase fractions where applicable, and texture are refined in consecutive cycles. The Rietveld analysis resolved an orientation distribution (OD) with $10^{\circ}$ angular resolution in orientation space. Figure 6e shows a stack of recorded $40^{\circ}$ spectra (bottom) and the Rietveld fit (top). The good agreement between experimental data and Rietveld fit gives confidence in the refinement. The OD was exported from MAUD and further processed in BEARTEX [54] to smooth $\left(7.5^{\circ}\right.$ Gaussian filter), rotate the sample coordinate system if necessary, and to calculate and plot pole figures used as a representation of texture. In the case of the two samples measured with the higher resolution SKAT spectrometer at Dubna, lattice parameters were refined; for Brg1618 they are $a=4.91005$ (1) and $c=5.40041(1)$ and for $\operatorname{Brg} 1643 a=4.91089(1)$ and $c=5.40120(1)$ with standard error of the last digit in parentheses.

Pole figures for Triassic quartzites are shown in Figures $7 \mathrm{a}-\mathrm{c}$ and S3, for layered quartz in Figure 8a,b, for muscovite in some samples in Figure 9, and for some adjacent Triassic marbles in Figure 10. Quantitative information about (0001) pole figure maxima and the texture index J are summarized in Table 1. Note that to refine the texture of monoclinic muscovite the first monoclinic setting with [001] as 2-fold axis has to be used [55]. In this setting the cleavage plane is (100). In Figure 9 labels correspond to the second setting which is more common in mineralogy, with (001) as cleavage plane.

\subsection{SEM-EBSD}

Selected samples were also measured by backscatter electron diffraction (EBSD) with a scanning electron microscope (SEM), particularly to explore the importance of mechanical Dauphiné twinning. EBSD data were collected at the Department of Earth and Planetary Science at the University of California, Berkeley, using a Zeiss EVO MA10 SEM, an EDAX Digiview IV high resolution detector, and TSL Orientation Imaging Microscopy (OIM) software. Diffraction images were first reduced and analyzed with OIM and then orientation data were exported and processed with the routine MAPTEX in BEARTEX [54]. Samples were prepared using standard petrographic techniques with a final high polish achieved with colloidal silica. All EBSD samples were uncoated and SEM vacuum was set to 10 Pascal variable pressure to reduce charging. SEM beam voltages and current varied from 15 to $25 \mathrm{kV}$ and 2 to $3 \mathrm{nA}$, respectively, but for high resolution data on finely crystalline areas, settings of $15 \mathrm{kV}$ and $2 \mathrm{nA}$ were most appropriate. The $2 \times 2$ binning with long exposure times of \pm 1 frame/sec produced best results. Pole figures were derived from large numbers of individual orientation data collected across the sample (commonly 20,000-150,000 points per scan). For each point the full crystal orientation (decribed by Euler angles) was determined and these individual orientations were then entered into a $5^{\circ} \times 5^{\circ} \times 5^{\circ}$ orientation space in BEARTEX, without relying on harmonic functions. Data from 3 to 4 scans were combined and orientation distributions were then rotated to agree with the neutron diffraction pole figures.

Some characteristic EBSD maps are shown in Figure 11. The third Euler angle $\left(\varphi_{2}\right.$ in Bunge notation), which for trigonal quartz is within the 0 to $120^{\circ}$ interval, is used for color identification because it is sensitive to Dauphiné twinning. Dauphiné twins are related to the host by a $180^{\circ}$ (equivalent to $60^{\circ}$ for trigonal quartz) around the c-axis (the c-axis orientation is defined by the first two Euler angles, $\varphi_{1}$ and $\left.\Phi\right)$. Dauphiné twin boundaries are highlighted with yellow lines in the maps. Some information about the scans is summarized in Table 2 (see also Supplementary Material, Table S2). 


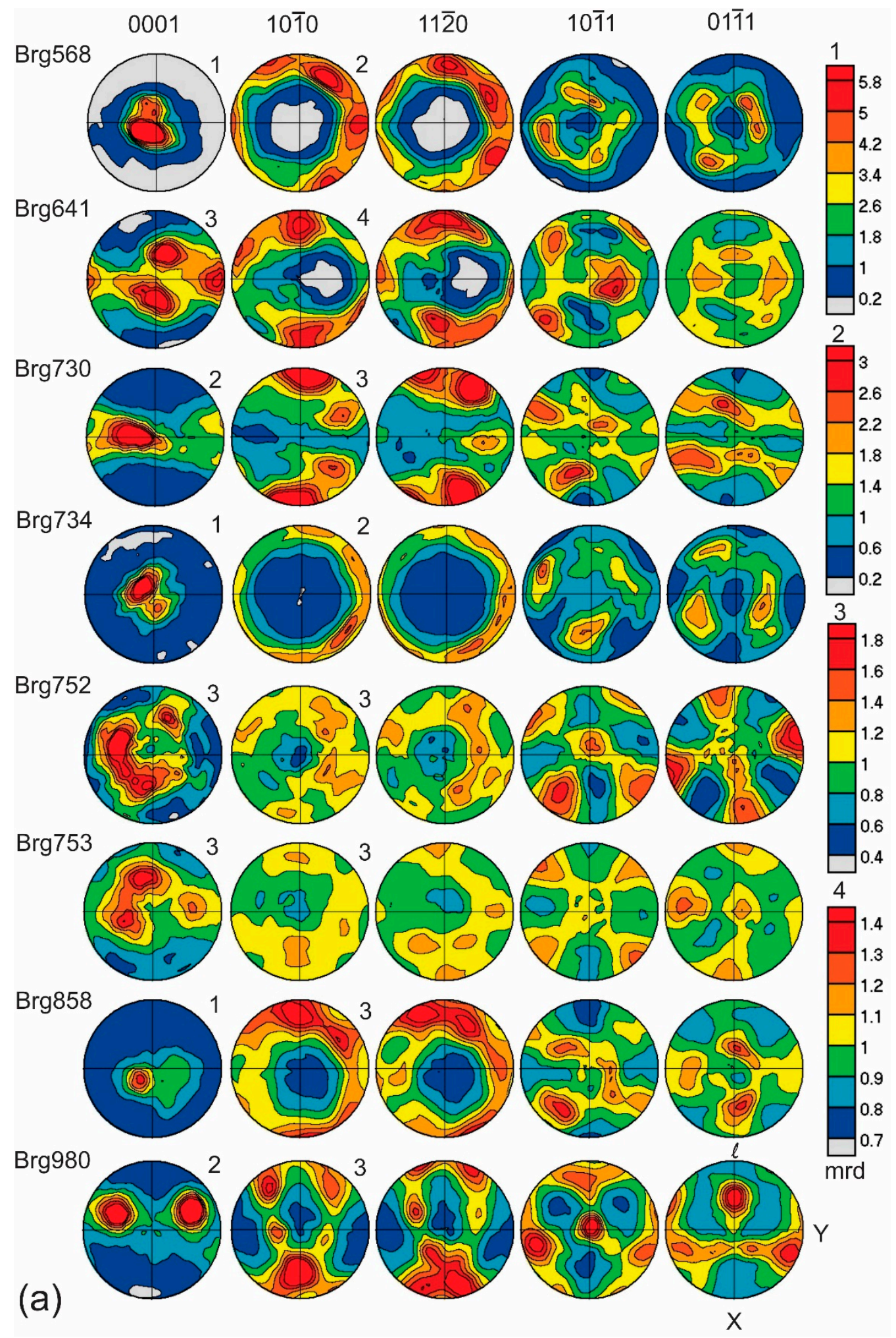

Figure 7. Cont. 


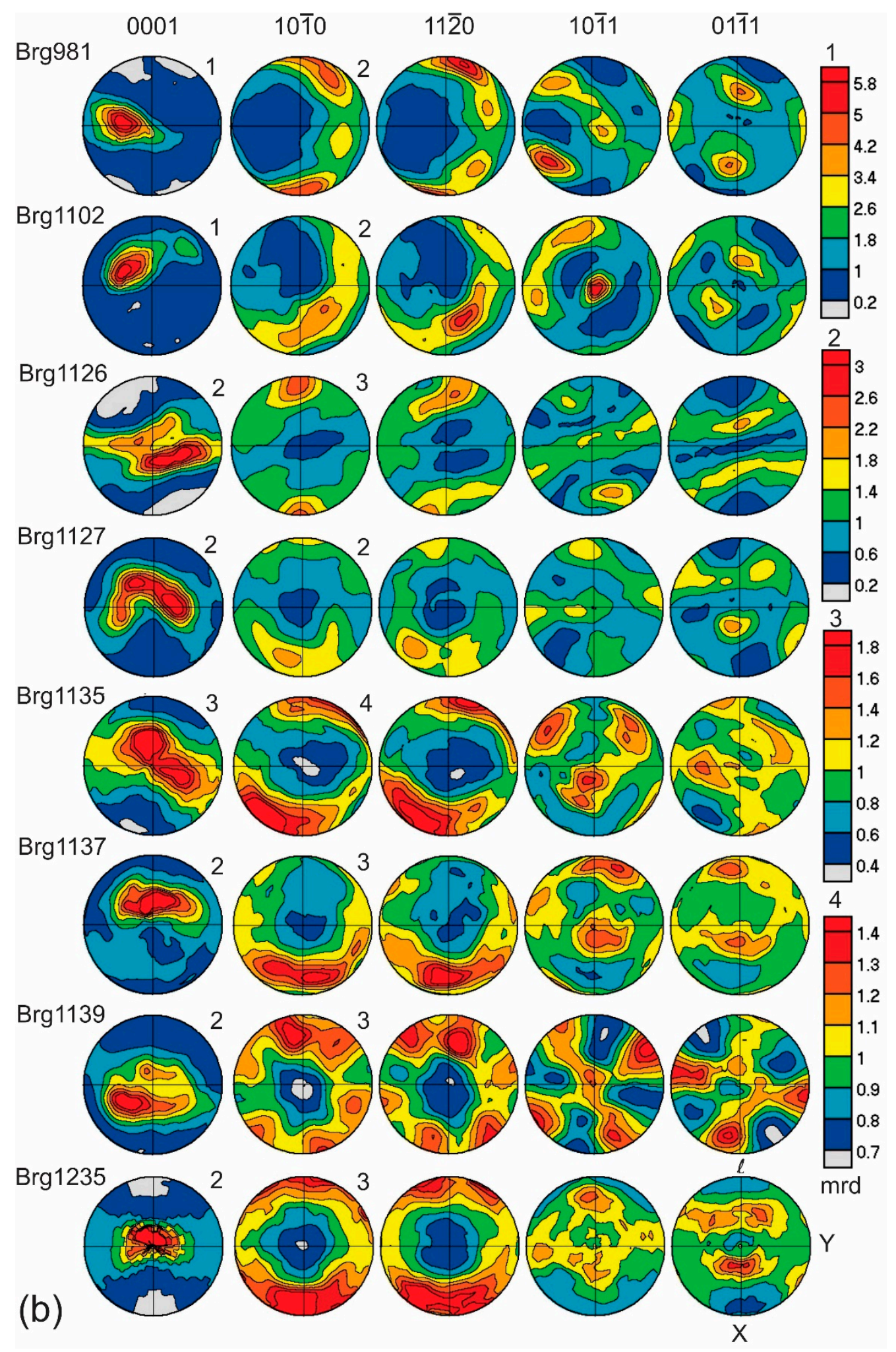

Figure 7. Cont. 


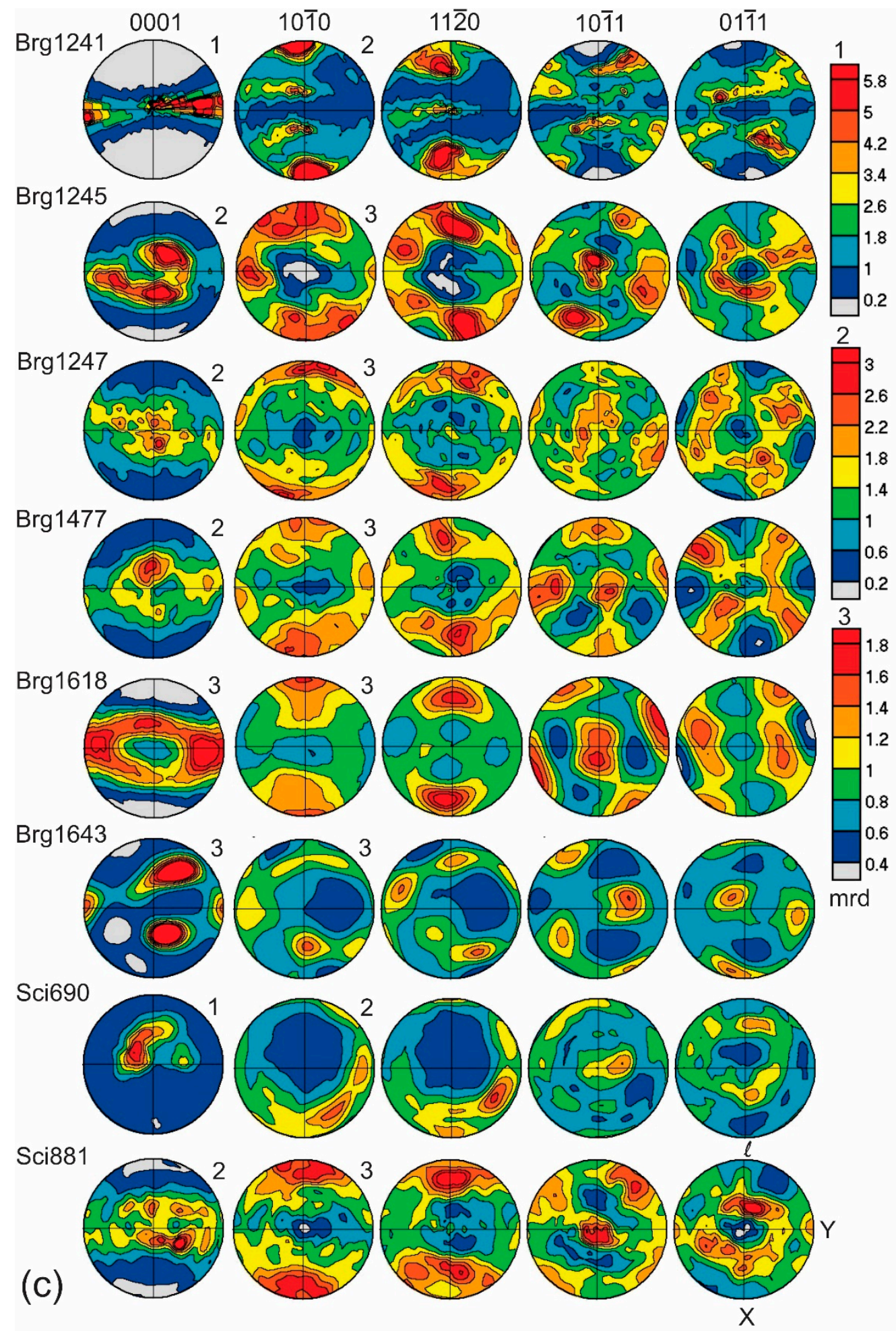

Figure 7. Neutron pole figures for quartz of Triassic quartzites. Equal area projection on the schistosity plane. Lineation is $l$. Numbers on top right of pole figures indicate which pole density scale was used (in mrd). The scale in the second column was also applied to Columns $2-5$. The order of samples is the same as in Table 1. 24 Triassic quartzites are divided on three figures (a), (b), (c). 


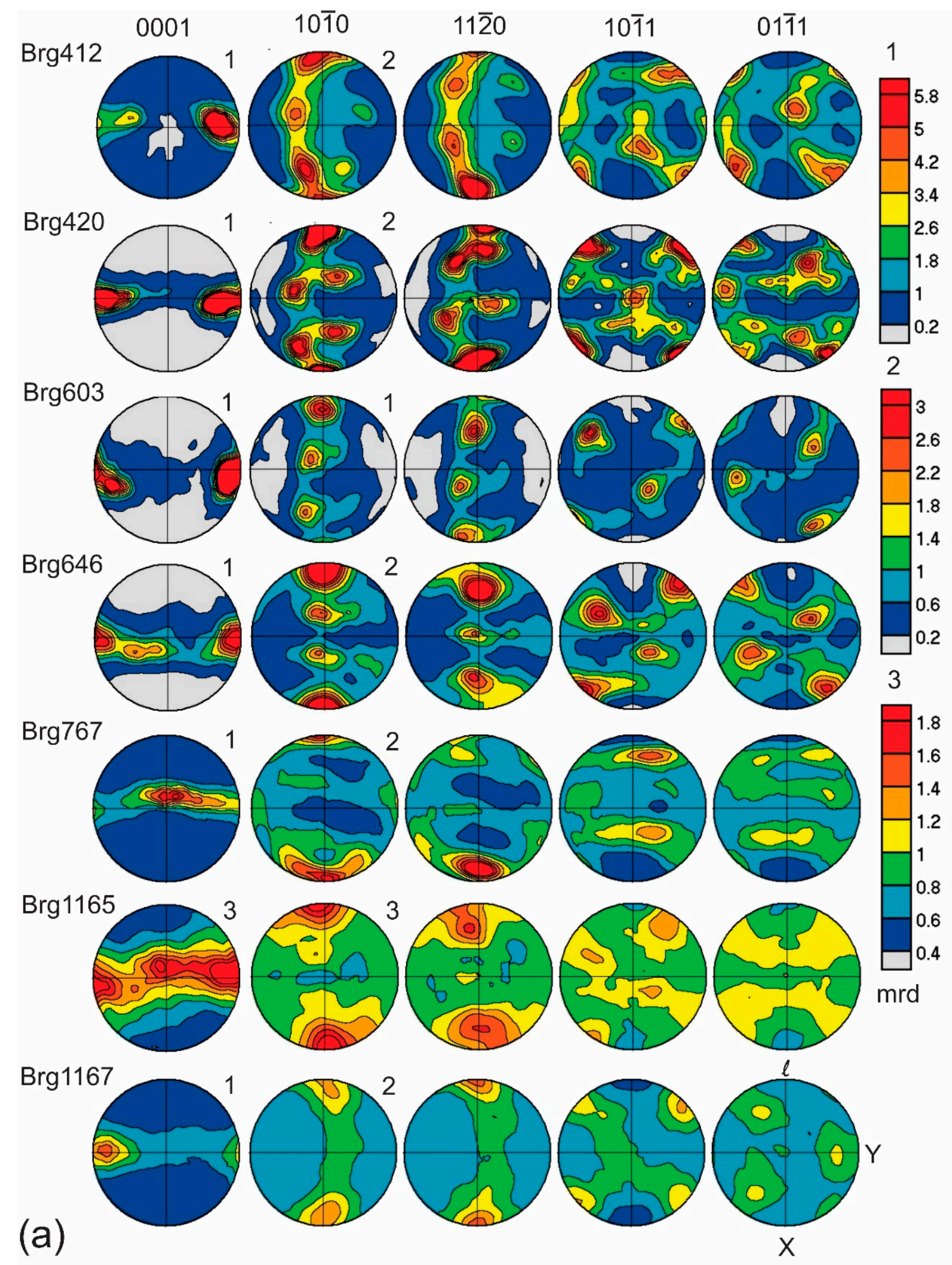

Figure 8. Cont. 


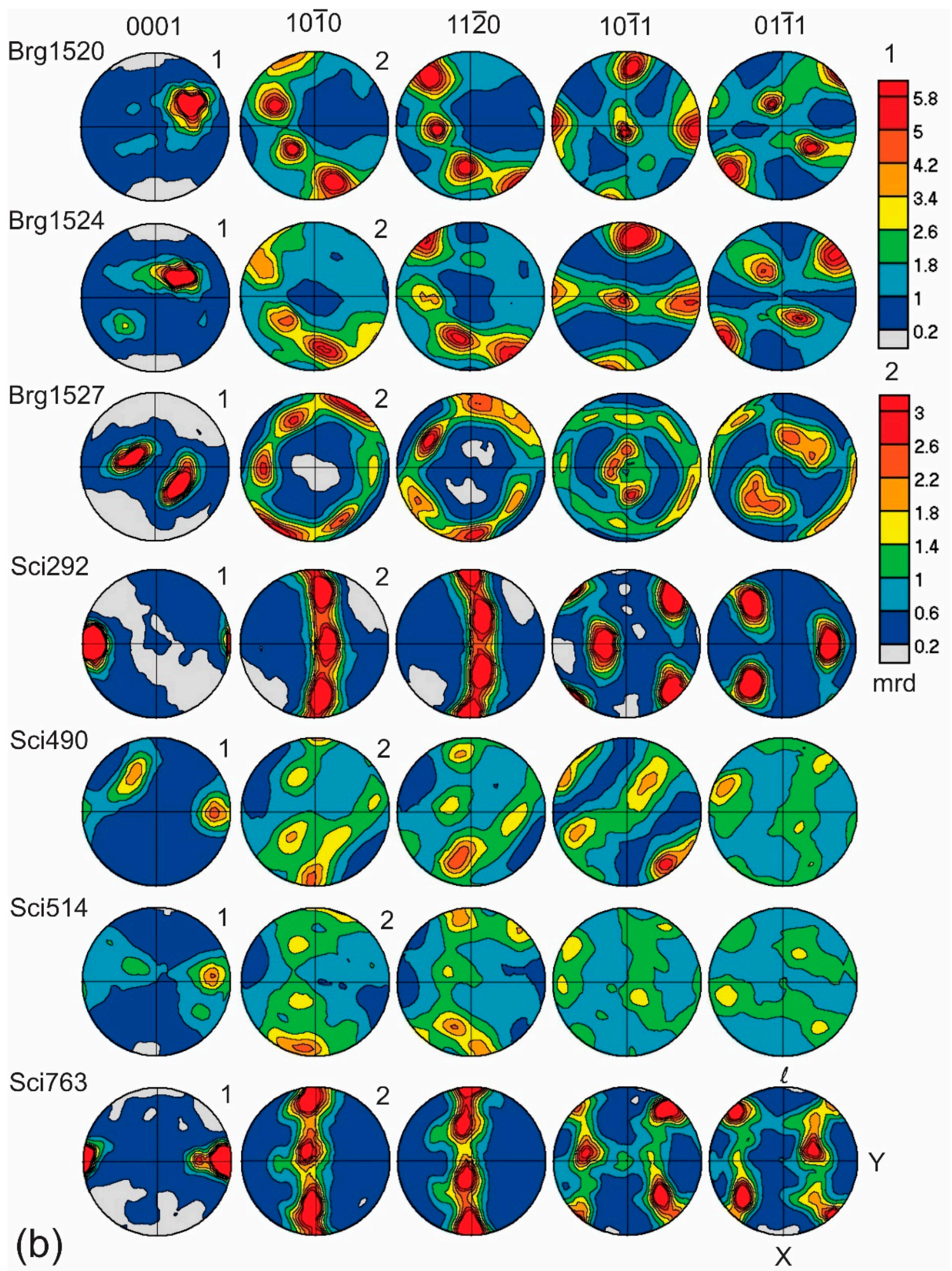

Figure 8. Neutron pole figures for quartz layers. Equal area projection on the schistosity plane. Lineation is $l$. Numbers on top right of pole figures indicate which pole density scale was used (in mrd). The scale in the second column was also applied to Columns $2-5$. The order of samples is the same as in Table 1. The 14 samples are divided into two figures, (a) and (b). 

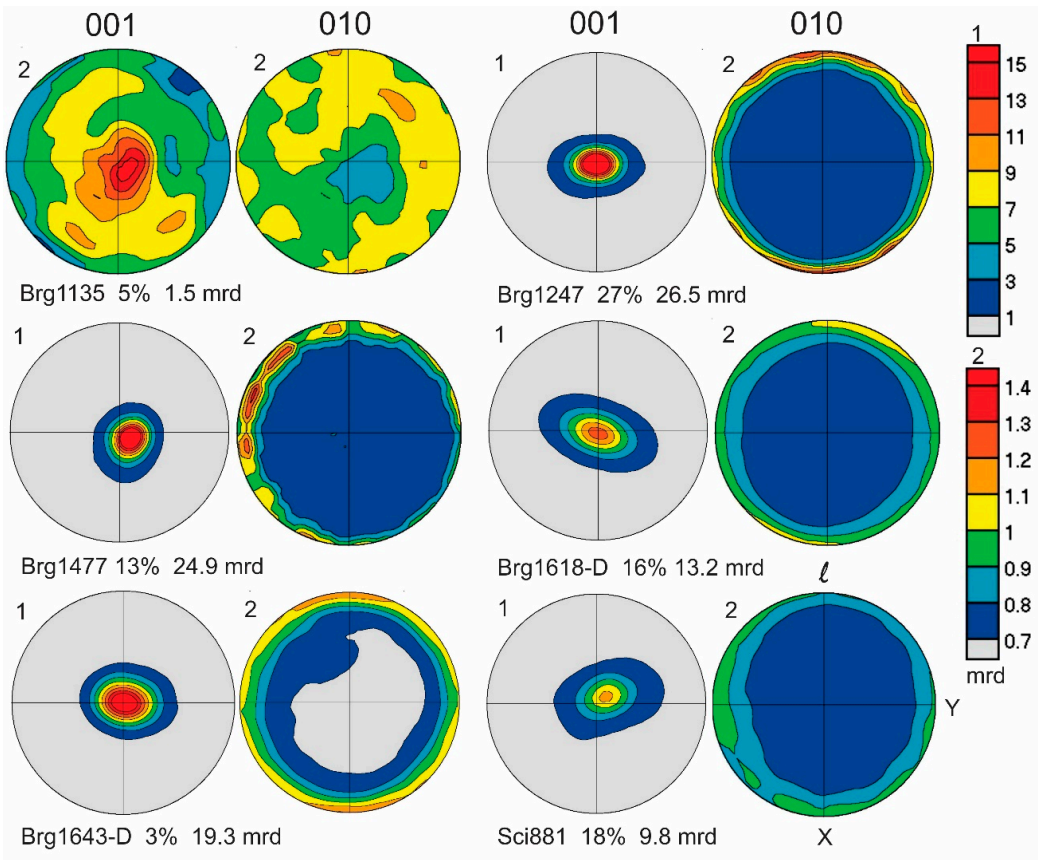

Figure 9. Neutron pole figures 001 and 010 of muscovite in Triassic quartzites. Equal area projection on the schistosity plane. Lineation is $l$. Numbers on top left of pole figures indicate the pole density scale that was used (in mrd). Next to the sample numbers are volume \% and maximum of the 001 texture peak. D after sample number indicates Dubna neutron data.

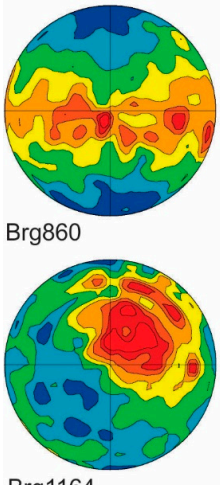

Brg1164

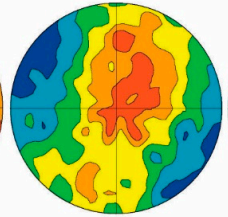

Brg1101 dolomite

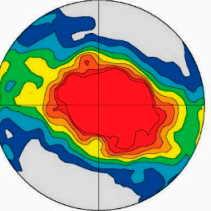

Brg1166

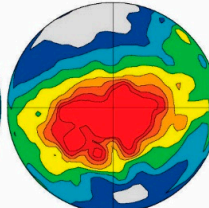

Brg1120

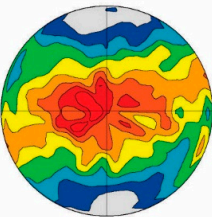

$\operatorname{Brg} 1243$

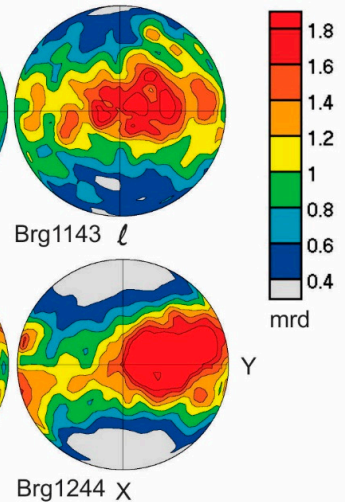

Brg1244 X

Figure 10. Neutron pole figures 0001 of calcite and dolomite in Triassic marbles. Equal area projection on the schistosity plane. Lineation is $l$. All samples are calcite except Brg1101 which is dolomite.

Table 2. EBSD twin boundary statistics. See also Table S2. The data in the table are obtained from the sum over individual scans. Selected data and twin boundaries are in pixels.

\begin{tabular}{ccccc}
\hline Sample & Area $\mathbf{( m m}^{\mathbf{2}} \mathbf{)}$ & Selected Data $\mathbf{( K )}$ & Twin Boundaries (K) & Inverse Ratio $\mathbf{1 0}^{\mathbf{- 2}}$ \\
\hline \multicolumn{5}{c}{ A: Triassic Quartzites } \\
\hline Brg568 & 2 & 586 & 16 & 2.6 \\
Brg641 & 3 & 844 & 7 & 0.8 \\
Brg980 & 4 & 629 & 10 & 1.6 \\
Brg981 & 3 & 730 & 14 & 2.0 \\
Brg1126 & 2 & 1540 & 24 & 1.6 \\
Brg1127 & 2 & 1116 & 11 & 1.0 \\
Brg1135 & 3 & 597 & 17 & 2.8 \\
Brg1137 & 2 & 407 & 22 & 5.4 \\
Brg1477 & 3 & 614 & 9 & 1.5 \\
\hline
\end{tabular}


Table 2. Cont.

\begin{tabular}{ccccc}
\hline Sample & Area $\mathbf{( m m}^{\mathbf{2}} \mathbf{)}$ & Selected Data (K) & Twin Boundaries (K) & Inverse Ratio $\mathbf{1 0}^{\mathbf{- 2}}$ \\
\hline \multicolumn{5}{c}{ A: Triassic Quartzites } \\
\hline Brg1618 & 5 & 1257 & 31 & 2.4 \\
Brg1643 & 4 & 2628 & 20 & 0.8 \\
Sci638 & 5 & 756 & 30 & 3.9 \\
Sci690 & 3 & 583 & 8 & 1.4 \\
Sci881 & 4 & 1113 & 37 & 3.3 \\
\hline \multicolumn{5}{c}{ B: Quartz Layers } \\
\hline Brg407 & 1 & 670 & 7 & 1.0 \\
Brg603 & 2 & 560 & 10 & 1.9 \\
Brg1167 & 4 & 1383 & 16 & 1.1 \\
Brg1520 & 3 & 729 & 3 & 0.4 \\
Brg1524 & 2 & 818 & 10 & 1.2 \\
Sci292 & 13 & 550 & 2 & 0.3 \\
Sci763 & 3 & 827 & 7 & 0.8 \\
\hline \multicolumn{5}{c}{ C: Comparison (see paragraph 5.7 below) } \\
\hline Br-undef-B & 4 & 331 & 5 & 1.4 \\
Br-300-A & 4 & 730 & 17 & 2.4 \\
Br3-A-500MPa & 1 & 114 & 2 & 1.7 \\
\hline
\end{tabular}

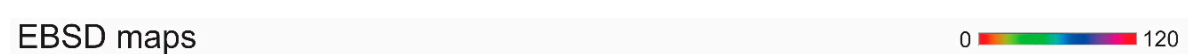
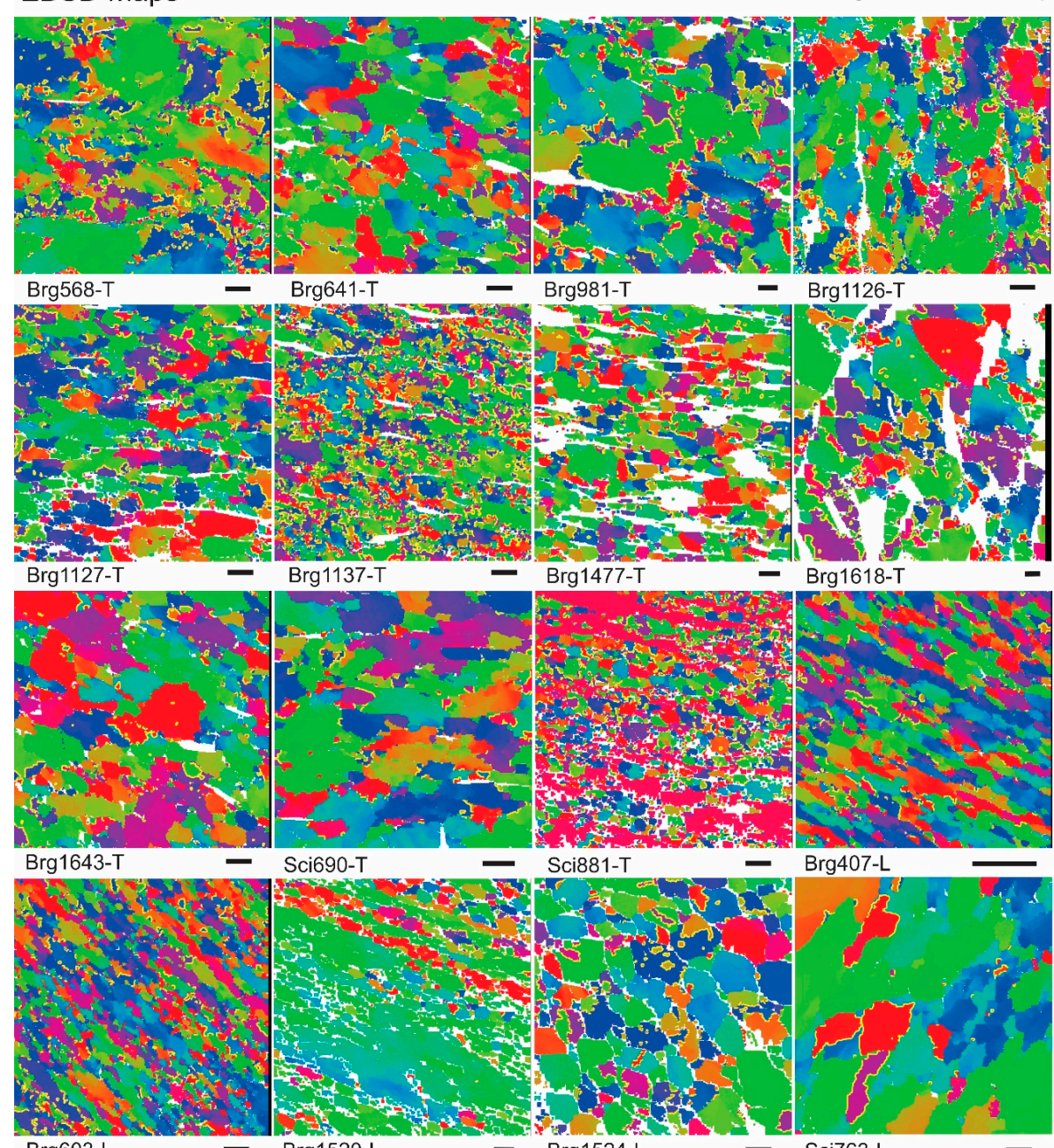

Sci690-T

- Sci881-T

Brg407-L
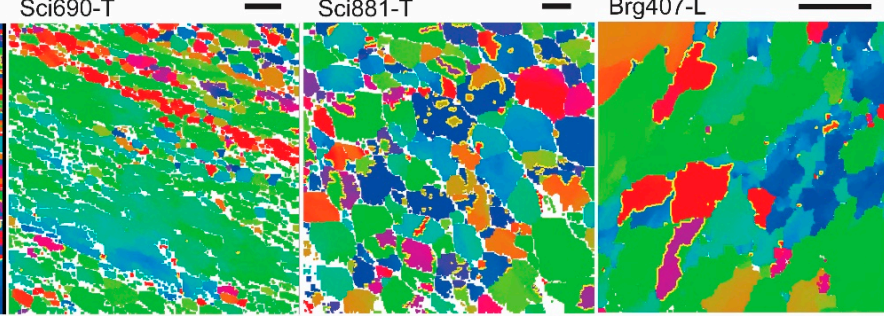

Brg603-L

- Brg1520-L

Brg1524-L

Sci763-L

Figure 11. Selected EBSD maps with Dauphiné twin boundaries (yellow). Colors shown on top right are based on Euler angle $\varphi_{2}$ that is sensitive to twinning. $T$ is for Triassic quartzites and $\mathrm{L}$ is for quartz layers. White are regions that could not be indexed and correspond mainly to muscovite. Scale bars are $100 \mu \mathrm{m}$. 


\section{Results}

The most simple patterns are pole figures for muscovite in Triassic quartzites with a strong (001) maximum perpendicular to the foliation (26.5 mrd for Brg1247 and $24.9 \mathrm{mrd}$ for Brg1477) and a more or less random distribution of (010) poles in the foliation plane for most samples (Figure 9). An exception is Brg1135 with a very weak texture $(1.5 \mathrm{mrd})$ and also a small volume fraction of muscovite $(5 \%)$.

The pole figures patterns for quartz have been divided into two groups: Triassic quartzites (Figure 7a-c) and quartz layers in crystalline basement (Figure 8a,b). As will become apparent in the discussion below, the large number of samples from a wide area is necessary to assess overall texture patterns and local variations.

For Triassic quartzites there is generally a concentration of c-axes at high angles to the foliation $\mathrm{Z}$ (center of the pole figure), in a few samples as a single maximum, often slightly asymmetric (e.g., Brg568, Brg734, Brg858, Brg1137, Brg1235, and Sci690). In many samples the distribution is more complex with a ZY-girdle developing around the pole to the foliation Z (e.g., Brg730, Brg1126, Brg1127, and Brg1139), in some cases with a well-defined double maximum (Brg641, Brg753, Brg980, Brg1245, Brg1618, and Sci881). In order to better visualize these distortions of the c-axis orientation patterns we chose this unconventional representation, projecting pole figures on the schistosity plane.

There is generally a concentration of $\{10 \overline{1} 0\}$ poles parallel to the lineation $l=\mathrm{X}$ such as Brg641, Brg730, Brg858, Brg1126, and Brg1235. A very distinct pattern is observed in $\{10 \overline{1} 1\}$ pole figures, with a maximum perpendicular to the foliation (center of the pole figures) and two maxima in the foliation plane, generally oblique to the lineation. $\{01 \overline{1} 1\}$ pole figures often have a minimum perpendicular to the foliation. Typical examples are Brg752, Brg753, Brg1139, Brg1245, Brg1477, Brg1618, and Sci881, but most samples show a similar trend, including samples only presented in Supplementary Material (Table S1 and Figure S3).

Maximum orientation densities vary greatly from sample to sample as summarized in Table 1. The highest (0001) pole densities are observed for Brg568 (12.4 mrd, J = 5.5), Brg734 (8.5 mrd, J = 3.6), and Brg1241 (8.8 mrd, J = 4.4), and relatively low ones for Brg753 (2.0 mrd), Brg1135 (2.3 mrd), and $\operatorname{Brg} 1618$ (2.3 mrd).

Pole figures from quartz layers are entirely different (Figure 8a,b). Most have a strong (0001) maximum in the foliation plane at $Y$, perpendicular to the macroscopic lineation X (e.g., Brg420, Brg603, Brg646, Brg1167, Sci292, and Sci763). Often there is a slight girdle distribution perpendicular to the lineation (e.g., Brg646, Brg1165, and Brg1167). Pole densities for (0001) are very high (e.g., Brg603-16.9 mrd, J = 11.9; Sci292-29.2 mrd, J = 18.4; and Sci763-26.3 mrd, J = 11.5) resembling a single crystal, even though these samples are very fine-grained (Figure 4). Correspondingly, other pole figures also have single crystal like orientation patterns, e.g., $\{10 \overline{1} 0\}$ and $\{11 \overline{2} 0\}$ pole figures have six characteristic maxima in the XZ plane (three are plotted on pole figures, and three are symmetrically distributed in the lower hemisphere). There are exceptions such as Sci490 and Sci514 with large grain size and close to the contact with the Tertiary Bergell granite. Here textures are complex, asymmetric and quite weak. This will be discussed later. Also in quartz layer textures there is a prevalence of $\{10 \overline{1} 1\}$ maxima perpendicular to the schistosity plane and corresponding $\{01 \overline{1} 1\}$ minima (Brg412, Brg420, Brg1520, and Brg1524).

EBSD analyses were performed on 21 samples, and on each sample 3-4 areas were scanned (Tables 1 and 2 and Supplementary Material Table S2). Some selected scan maps are shown in Figure 11. The different scans for each sample were combined for texture analysis. The white regions on the maps display mainly muscovite that was not taken into account in the EBSD analysis. The maps document considerable variation in grain size, in accordance with optical images (Figures 3 and 4). Some samples have high aspect ratios of the grain shape, such as Brg407, Brg603, and Brg1520, but in most samples grains are fairly equiaxed. On orientation maps Dauphiné twin boundaries, corresponding to a $60^{\circ}$ $\left(180^{\circ}\right)$ rotation around [0001], were identified with the subroutine MAPTEX in BEARTEX and the twin boundaries are plotted as yellow lines on the maps. Some scans display many twins (such as Brg1137 and Sci881) while other ones are almost free of twins (e.g., Brg641, Brg1643, Sci292, and Sci763). 
The twin boundary frequency has been quantified by dividing the total length of twin boundaries by the total scanned area. This "twin boundary density" in Table 2 shows a wide range from $4.9 \times 10^{-3}$ (most) to $0.3 \times 10^{-3}$ (least). Overall Triassic quartzites have more twin boundaries than quartz layers.

Crystal orientation patterns observed by EBSD were rotated to bring them into the same orientation as pole figures measured by neutron diffraction. Figure 12 compares some (0001) and $\{10 \overline{1} 1\}$ pole figures obtained with the two methods (see also Supplementary Material Figures S4 and S5 for a more complete comparison). There is excellent agreement in texture patterns. A comparison of texture maxima in pole figures reveals that EBSD pole figures have slightly sharper textures than neutron pole figures (Table 1). We will elaborate on differences between the two methods in the discussion.

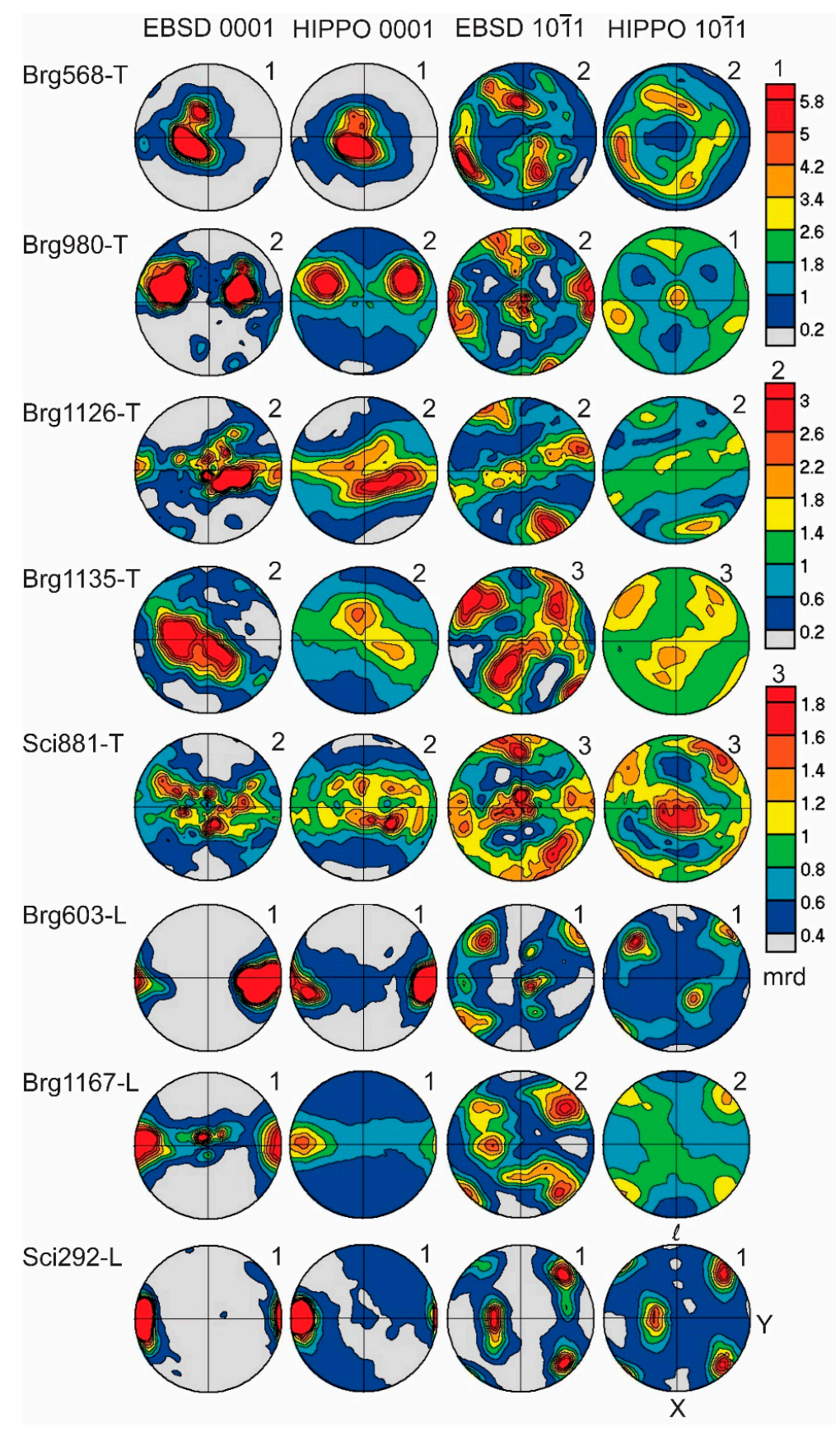

Figure 12. Comparison of selected EBSD and neutron pole figures 0001 and $10 \overline{1} 1$ (for a complete display see Supplementary Material Figures S4 and S5). Equal area projection on the schistosity plane. Lineation is $l$. Numbers on top right of pole figures indicate which pole density scale was used (in mrd). 
Adjacent to Triassic quartzites (transformed from sandstones) are calcite and dolomite marbles (transformed from Triassic limestones). Figure 10 shows some of the pole figures from marble samples. Overall there is a (0001) maximum perpendicular to the foliation, but this can be asymmetric (e.g., Brg860 and Brg1244) relative to the schistosity plane and lineation, which can vary over small distances (e.g., Brg1164 and Brg1166, and Brg1243 and Brg1244). The strength of preferred orientation ranges from $1.8 \mathrm{mrd}$ to $3 \mathrm{mrd}$ for (0001) maxima (Table 1).

\section{Discussion}

\subsection{Quartz Texture Types}

The 47 quartzite samples, collected over a large area in the Southern Alps, display consistent patterns of preferred orientation. In metamorphic sandstones c-axes are oriented at high angles to the foliation plane, $\{10 \overline{1} 0\}$ poles with a maximum parallel to the lineation, and poles to $r=\{10 \overline{1} 1\}$ with a concentration perpendicular to the foliation. In quartz layers from the crystalline basement the most common pattern is c-axes in the foliation plane and perpendicular to the lineation. Also here, $\{10 \overline{1} 0\}$ poles have a maximum parallel to the lineation, but there is more diversity, especially in layers close to the contact with the Bergell granite. Given that these samples originate from an area covering around $400 \mathrm{~km}^{2}$, it was really surprising that texture patterns could be divided into two distinct groups: Triassic metasedimentary quartzites (Figure 7) and layers of quartz in schists and gneisses (Figure 8), both of comparable metamorphic grade and existing in close proximity.

Looking at c-axes alone, the patterns described in the literature (first by Sander 1950 [2]) can be divided into four basic types in a sample coordinate system $X Y Z$, with $X$ as lineation and $Z$ normal to the foliation: Type A with a simple maximum, sometimes asymmetric, at $Z$ (Figure 13A); Type B a ZY girdle or crossed girdle (Figure 13B); Type $C$ a small circle girdle around $Z$ (Figure 13C); and Type D a simple maximum at $Y$ (Figure 13D). Figure 13a uses the projection geometry applied in this paper and Figure $13 \mathrm{~b}$ the more common projection geometry used in the literature. As was mentioned earlier the geometry in Figure 13a is optimal to display complexities in distributions for (0001) and $\{10 \overline{1} 1\}$ pole figures.

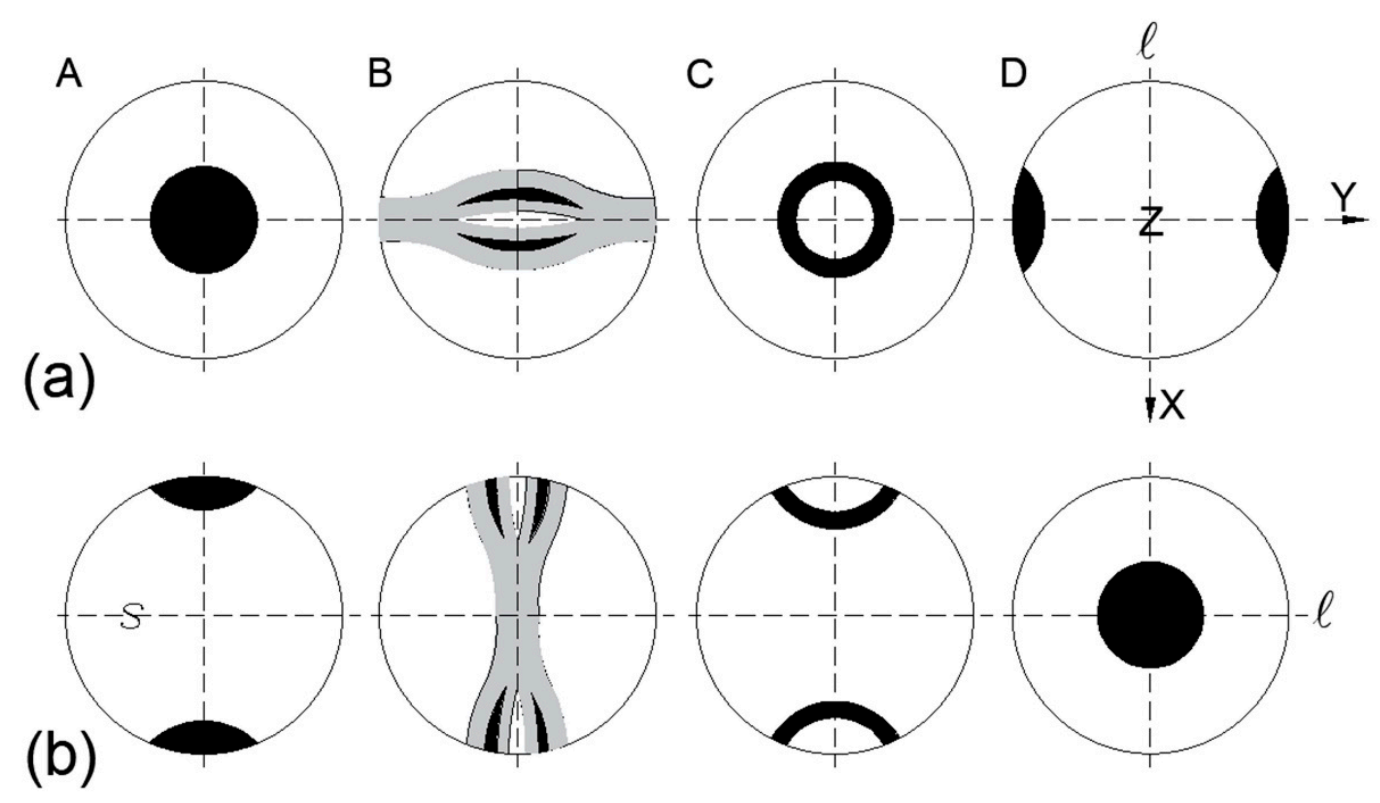

Figure 13. Schematic of quartz c-axis texture types relative to sample coordinates $\mathrm{X}, \mathrm{Y}$, and $\mathrm{Z}$. (a) Projection on the foliation plane $X Y$ used in this paper. $X$ is the lineation $l$. A: c axes perpendicular to foliation; B: crossed girdle; C: c-axis small circle girdle; and D: c-axis maximum at Y. (b) More conventional projection on the plane $\mathrm{XZ}$ defined by the normal to the foliation $s$ and the lineation $l$. 
In deformation experiments at relatively low temperature Type A was generally observed, with a maximum of c-axes in the compression direction. This was attributed to dominant basal slip as deformation mechanism [56]. At these conditions grains are highly flattened. At higher temperature and significant recrystallization this pattern transformed to a small circle of c-axes about the compression direction (Type C). This was confirmed in experiments near the brittle-ductile transition [57]. In plane strain/pure shear, with compression along $Z$ and extension along $X$, the (0001) maximum transforms into Type B with a YZ girdle [58]. In simple shear the c-maximum becomes asymmetric and is centered against the sense of shear [59].

In natural quartz fabrics at low metamorphic grade Type A fabrics were described $[60,61]$ as well as girdle-type B fabrics [12]. A transition of a crossed girdle (Type B) transforming with increasing temperature into a small circle (Type C) was first described by Behr [3-5] for the Saxony granulite terrain and elaborated by Lister and Dornsiepen [6]. The Type $C$ small circle girdle was also observed in amphibolite quartzites in the Central Alps [62]. A transition from a girdle fabric (Type B) to a $\mathrm{Y}$ maximum (Type D) with increasing metamorphic grade was described in quartz layers from the Simplon area in the Alps [14]. A study of schists in the Annapurna region of Nepal revealed a transition from a c-maximum in $\mathrm{Z}$ (Type A) to a cross girdle (Type B) and finally to a $\mathrm{Y}$ maximum (Type D) with increasing grade [15]. Many samples with D-type fabrics underwent recrystallization and display equiaxed grain shapes. A transition from a Z-maximum (Type A) to a YZ girdle (Type B) was documented in Montalto/Italy quartzites [63] as well as in Mt. Isa/Australia gneisses [64].

The conspicuous Y maximum (Type D) appears strongly linked to mylonitic deformation and recrystallization at high temperature, for example in amphibolite facies mylonites from the Swedish Caledonites [64], Galicia and Saxony granulites [65], and in the Pyrenees [66]. A transition from the small circle fabric (Type C) to the $Y$ maximum type with increasing metamorphic grade and recrystallization was documented for the Ryoke belt/Japan [67] and for ultrahigh pressure gneiss in Norway [68] and attributed to a transition from basal to prismatic slip. Other reports of type D fabrics in mylonites are from the Moine thrust in Scotland [69,70], the Santa Rosa mylonite zone in California [48], deformed Adamello tonalities [71,72] and sheared quartz layers from the southern Simplon area in the Italian Alps [14]. In all these cases quartz textures are very strong and fabrics are recrystallized.

The asymmetry of c-axis textures relative to fabric coordinates, especially the Type A texture with a maximum near $Z$, has been attributed to simple shear [7,66,73-82]. Lister and Williams [83] discussed the relationship between texture asymmetry and sense of shear in detail and there has been considerable ambiguity. In most cases the c-maximum near $\mathrm{Z}$ is displaced against the sense of shear. This interpretation is based on experiments $[58,84,85]$ and polycrystal plasticity deformation models assuming dislocation glide [78,86-88].

\subsection{Bergell Quartz Textures}

After this brief overview of some significant studies of natural quartz textures, let us return to Bergell quartzites and put them into this context. It should be emphasized again that most of older studies focus on c-axis distributions, with a few exceptions taking the trigonal symmetry of quartz into account $[22,48,65,88]$. In most of the Bergell quartzites there is a significant difference between positive rhombs $\{10 \overline{1} 1\}$, which are elastically soft directions and negative rhombs $\{01 \overline{1} 1\}$ that are approximately twice as stiff [89]. This difference in rhombohedral distributions is observed in most of the pole figures in Figures 7 and 8.

Of the Bergell quartz layer samples four are true mylonites (Brg407, Brg412, Brg603, Sci292) with highly flattened fine-grained quartz $(\sim 100 \mu \mathrm{m} \times 10 \mu \mathrm{m})$ warping around feldspar clasts (Figures 4 and 5). The Type D texture resembles a single crystal and is similar to those observed in Santa Rosa [48]. In the Bergell Alps these samples are from the deepest tectonic level, Gruf migmatites, underneath the Northern limb of the Tertiary Bergell granite and are subjected to amphibolite/granulite facies metamorphism. Other samples of quartz layers in the vicinity of the Bergell granite contact also 
approach a single crystal texture, but the orientation is more asymmetric relative to the foliation and lineation. Quartz is also highly deformed and partially recrystallized (Brg1165, Sci490, and Sci514). Interestingly the high-grade mylonitic Type D textures (Figure 8a,b) are not too different from those in quartz layers in the upper nappes of lower metamorphic grade such as Brg646 (Tambo nappe) and Brg1167 (Suretta nappe). Were these textures inherited from a previous igneous event? They are all in the vicinity of older Hercinian granites. Three samples from the basement of higher Austroalpine nappes have a more complex pattern that also may be attributed to an older deformation process (Brg1520, Brg1524, and Brg1527).

For a majority of quartz layers textures display a $\{10 \overline{1} 0\}$ maximum in the lineation direction. Exceptions are Sci292 and Sci763, with a $\{11 \overline{2} 0\}$ maximum. Also, often there is a $\{10 \overline{1} 1\}$ maximum perpendicular to the foliation.

Next we have a closer look at metamorphosed Triassic quartzites. They all form coherent layers on top of Paleozoic metamorphic rocks in a stack of nappes from the low Pennine Tambo nappe to the high Austroalpine Margna nappe. All samples have an excellent foliation (Figure 2), defined by highly oriented muscovite (Figure 9). On cleavage surfaces a good lineation is generally visible. Contrary to quartz layers, preferred orientation is much weaker, ranging for (0001) from 2 to 12 mrd. (Table 1). The microstructure displays fairly equiaxed grains for most samples. A few have higher aspect ratios up to 5:1 (e.g., Brg568, Brg1127, Brg1137, Brg1241, and Sci881, see Figure 3). Some samples display a relatively simple c-axis maximum perpendicular to the foliation (Brg568, Brg734, Brg858) (Type A) but for most this maximum is fairly asymmetric, splitting into double maxima and a crossed girdle $Y Z$ (Type B) (Figure 7a-c).

Some quartzites display abundant deformation lamellae (e.g., Brg1127 and Brg1618, highlighted by arrows in Figure 5). Such lamellae have first been mentioned by Sander 1950 (his Figure 41) [2] and later were investigated in detail [90-96] and have been attributed to low temperature deformation associated with dislocation activity. The lamellar structures are particularly abundant during shock deformation [97-101]. It is likely that basal slip $(0001)<11 \overline{2} 0>$ has been an active slip system in samples showing deformation lamellae [91-94].

There is overall an alignment of $\{10 \overline{1} 0\}$ and in some cases $\{11 \overline{2} 0\}$ parallel to the lineation (Figure $7 \mathrm{a}-\mathrm{c}$ ). While c-axis distributions can be quite variable, there is a persistent pattern in $\{10 \overline{1} 1\}$ pole figures with a maximum perpendicular to the foliation (Z) (good examples are Brg752, Brg1102, Brg1139, Brg1245, Brg1477, Brg1618, and Sci881). This could be conceivably due to mechanical Dauphiné twinning [20,102], but EBSD observations show that twin boundaries still exist and these twins did not propagate through the crystal under an applied stress. Note that Dauphiné twinning would have no effect on c-axis and a-axis distributions and the accommodated plastic strain is minimal. Another reason for the difference between $(10 \overline{1} 1)$ and $(01 \overline{1} 1)$ pole figures could be deformation on rhombohedral slip systems as explained below.

\subsection{Polycrystal Plasticity Modeling}

Polycrystal plasticity modeling of quartz was initiated by applying the Taylor theory, focusing on basal and prismatic slip in axial deformation [86,87] and in simple shear [83]. Later the viscoplastic self-consistent theory VPSC [103,104] was applied to quartz [78,105]. Morales et al. [88] conducted a systematic study applying VPSC to model texture patterns of quartz polycrystals deformed in axial compression and in simple shear for a wide range of slip systems, including basal, prismatic and rhombohedral. For basal (c)<a > slip a [0001] maximum develops parallel to the compression direction (Type A). For prismatic $\{\mathrm{m}\}<\mathrm{a}>$ slip a c-maximum in $\mathrm{Y}$ develops in simple shear at high strain (Type D).

Here we have applied VPSC to explore if observed texture patterns in our natural quartzites can be explained with deformation by dislocation glide. For this we used the Los Alamos VPSC6 code [104]. Initially 2000 randomly oriented ellipsoidal grains rotate during deformation by slip in an anisotropic viscous medium representing the average of all grains and being updated at each deformation step. It is assumed that the stress exponent for the slip systems is 3, corresponding to creep conditions. 
No work-hardening of slip systems was applied. The grain shapes were updated up to a ratio of 5:1. The aggregate was deformed to an equivalent strain of 0.5 and 1.0 in 50 and 100 steps, correspondingly.

In Figure 14 we show results for three conditions. Many others were explored. Model 1 assumes plane strain/pure shear with extension along $X$ and compression along $Z$. Critical shear stress (CRSS) for the $(0001)<11 \overline{2} 0>(\mathrm{c}<\mathrm{a}>)$ system is 2 , for the $\{10 \overline{1} 1\}<\overline{1} 2 \overline{1} 0>(\{\mathrm{r}\}<\mathrm{a}>)$ system is 1 , and for $\{10 \overline{1} 1\}<\overline{1} 123>$ $(\{\mathrm{r}\}<\mathrm{p}>)$ is 4 . Average slip activities after 50 steps are $16 \%$ for $\mathrm{c}<\mathrm{a}>, 42 \%$ for $\{\mathrm{r}\}<\mathrm{a}>$, and $22 \%$ for $\{\mathrm{r}\}<\mathrm{p}>$. The resulting pole figures (Figure 14a) show a split maximum/girdle of $(0001)$ around $Z$, a $\{10 \overline{0} 0\}$ maximum at $X$ and oblique concentrations for $\{10 \overline{1} 1\}$. The pattern is very similar to many Triassic quartzite textures including Brg752, Brg1139, and Brg1245 (Figure 7). Increasing the CRSS for $\{10 \overline{1} 1\}$ slip increases c-slip and creates a simple maximum in Z. Increasing the CRSS for (0001) opens the (0001) girdle, with maxima closer to $Y$ as observed in Brg1618 and Brg1643 (Figure 7c).

Model 2 attempts to generate a texture with a (0001) maximum at $Y$. This can be obtained again in pure shear with compression along $Z$ and extension along $X$, and an active slip system $\{10 \overline{1} 0\}<\overline{1} 2 \overline{1} 0>$ $(\{\mathrm{m}\}<\mathrm{a}>$ ) with CRSS equal to 1.0 (Figure $14 \mathrm{~b})$. Only $\{\mathrm{m}\}<\mathrm{a}>$ is active after 50 and 100 steps. The pattern with a (0001) maximum at $\mathrm{Y}$ and a $\{10 \overline{1} 0\}$ maximum at $\mathrm{X}$ resembles textures in high grade mylonites such as Brg412, Brg603, and Sci292 (Figure 8). Microstructures indicate recrystallization, but this may not change the overall texture pattern greatly as will be discussed below.

Model 3 reproduces simple shear conditions described by Morales et al. 2014 (their Figure 15a, top right) [88] to generate a texture with a maximum in $Y$. The active slip system is again $\{10 \overline{1} 0\}<\overline{1} 2 \overline{1} 0>$ $(\{\mathrm{m}\}<\mathrm{a}>$ ) with CRSS equal to 1.0 (Figure 14c). Also in simple shear only $\{\mathrm{m}\}<\mathrm{a}>$ slip is active. The resulting pattern is again a (0001) maximum at $Y$ which, compared with pure shear, develops only at high strain. The $\{10 \overline{1} 0\}$ maximum is rotated relative to the pure shear texture. We expect that in natural mylonites there is generally a dominance of plane strain, with a variation in pure shear and simple shear as documented from xenolith geometry in Palm Canyon mylonites [106]. Note that

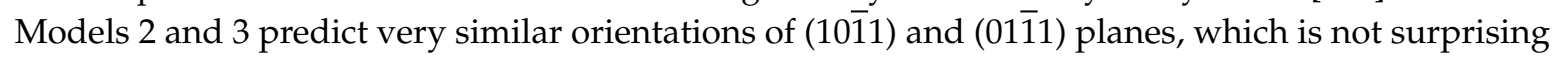
since rhombohedral slip systems are not significantly active (and were assigned high CRSS values).

Only three model results are shown in Figure 14 and they show good agreement with some of the natural quartz textures. Similar fits could be obtained for most samples by slightly modifying the relative critical shear stresses of active slip systems (i.e., the balance between basal, rhombohedral, and prismatic slip) and the applied strain geometry (such as plane strain versus shortening, pure shear versus simple shear in plane strain). It appears that for most quartzites plane strain dominates, except for some Triassic quartzites where shortening may dominate ((0001) maximum perpendicular to schistosity). Also, for Triassic quartzites the overall strain is moderate ( 0.5), while for mylonitic quartzites it is considerably higher.

\subsection{Multiphase Issues}

In all Triassic quartzite samples with significant mica content, muscovite displays a very simple symmetrical pattern with a (001) maximum perpendicular to the cleavage/foliation plane and no evidence for lineation (Figure 9). Muscovite content ranges from 3\% (Brg1643) to 27\% (Brg1247) and for most quartzites (except Brg1135) muscovite textures are very strong (10 mrd to $18 \mathrm{mrd}$ ). Generally muscovite platelets grew during recrystallization, with not much evidence for bending or kinking (e.g., Figure 5). Why are quartz textures with significant muscovite content weak, compared with quartz layers which are almost monomineralic? Muscovite locally shields stress and effectively decreases the efficiency of recovery-controlled dislocation motions as documented by experiments [107-110] and plasticity models that take local grain interaction into account [111]. Also muscovite inhibits grain boundary motion during dynamic recrystallization. The texture of Triassic quartzites is similar to that documented in underlying muscovite gneiss from the Tambo nappe that transformed from old granite, with also very strong muscovite texture $(10.0 \mathrm{mrd})$ and a much weaker quartz texture $(1.7 \mathrm{mrd})$ [112]. 


\subsection{Textures of Associated Marble}

Triassic quartzites are overlain by marble (metamorphic limestone, "Muschelkalk") that is mechanically much weaker and may absorb much of the strain, often with local heterogeneities as expressed in calcite and dolomite pole figures (Figure 10). Optical microstructures of most marble samples display intense mechanical twinning and this appears to be a major mechanism at relatively low temperature $[113,114]$. The $(0001)$ maximum at high angles to the foliation plane is consistent with observations on Yule marble [115] and Carrara marble [116-119], both in natural samples and during deformation experiments in various geometries. Similar textures are also observed in marbles from the Alps [120] and the Pyrenees [121]. The asymmetry of the calcite fabric has been investigated in detail in experiments [122,123] and by modeling [124] and can be attributed to a simple shear component. One sample of Triassic dolomite from Casaccia (Brg1101) displays a relatively weak texture and also a maximum perpendicular to the foliation (Figure 10). A similar pattern was observed in other Alpine dolomites [125] and in the deformation experiments [126]. The observations suggests that marble adjacent to Triassic quartzite in the Bergell area is strongly deformed with an often asymmetric pattern.

(a)

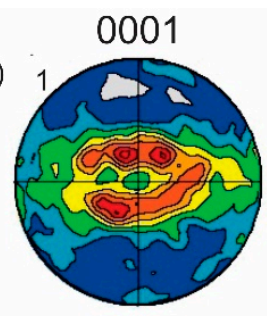

Pure shear $X+Z-c-a=2$, ra=1, $r p=4$, strain 0.5

(b)
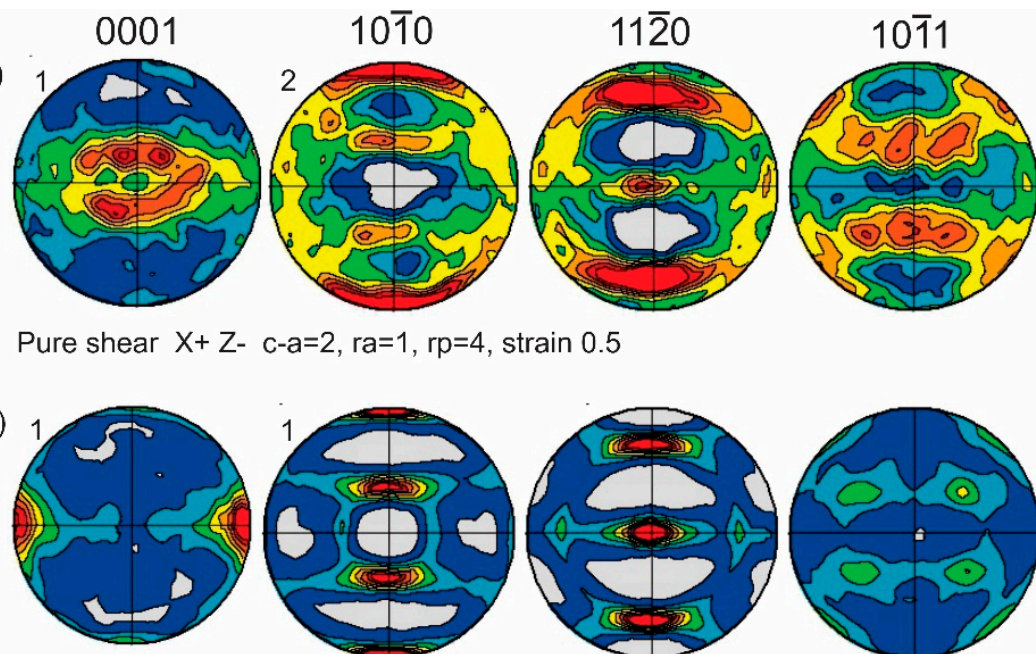

Pure shear $X+Z-m-a=1$, strain 1.0

(c)

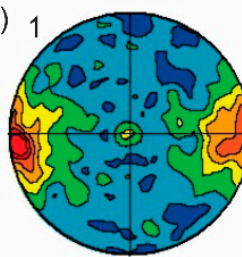

Simple shear $\mathrm{X} / \mathrm{Z} \mathrm{m}-\mathrm{a}=1$, strain 1.0
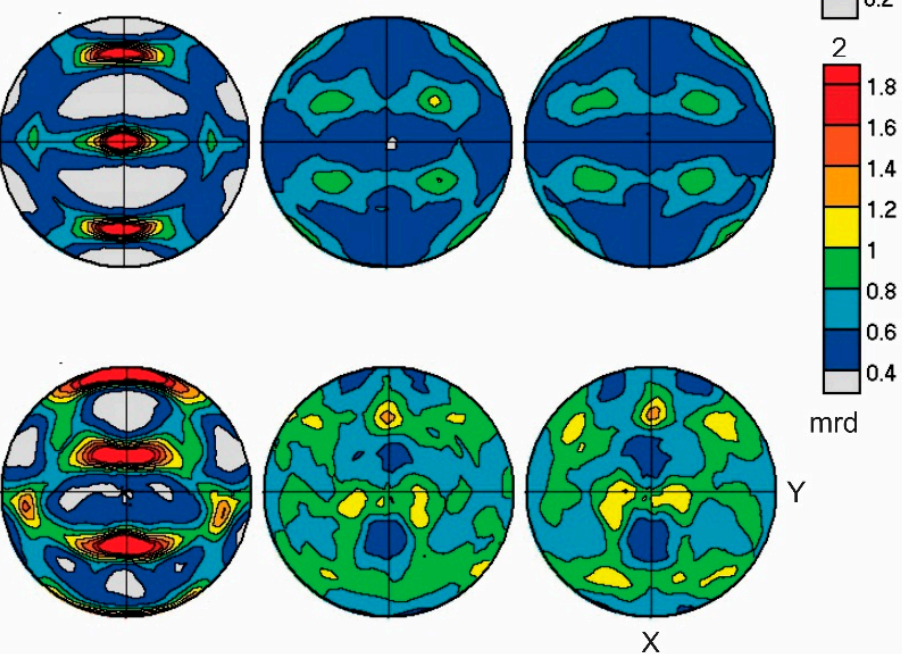

Figure 14. Viscoplastic self-consistent VPSC modeling of quartz textures. (a) Pure shear Z compression, $X$ extension, equivalent strain 0.5 , basal $(0001)<2 \overline{11} 0>(\mathrm{c}<\mathrm{a}>)$, and rhombohedral slip $\{10 \overline{1} 1\}<\overline{1} 2 \overline{1} 0>$ $(\{\mathrm{r}\}<\mathrm{a}>)$. (b) Pure shear $Z$ compression, $X$ extension, equivalent strain 1.0, prismatic slip $\{10 \overline{1} 0\}<\overline{1} 2 \overline{1} 0>$ $(\{\mathrm{m}\}<\mathrm{a}>) .(\mathrm{c}) \mathrm{XZ}$ plane strain, simple shear, $X$ shear direction, equivalent strain 1.0, and prismatic slip $\{10 \overline{1} 0\}<\overline{1} 2 \overline{1} 0>$. Equal area projection.

\subsection{Dynamic Recrystallization}

Another aspect of quartz texture formation is dynamic recrystallization for which there is ample evidence in microstructures with grain growth of individual crystals (e.g., Brg1241) to an ideal mosaic microstructure (e.g., Brg1524) (Figures 3-5). Axial compression experiments with recrystallization observed a transition from a c-axis maximum parallel to the compression (Type A) to a small circle girdle (Type C) [57] and simple shear experiments a transition from Type A, to a XY girdle (Type B), 
and ultimately, to a Y maximum $[84,85]$. Experiments also established that trace water content has a significant impact on recrystallization [72,127-132].

Interpretation of grain growth in a stress-strain environment is complex [132,133]. It has been approached with thermodynamics and is fairly straightforward for materials, which are elastically highly anisotropic such as mica [134-136]. For quartz in compression one would expect alignment of the soft direction $\{10 \overline{1} 1\}$ parallel to the compression direction, with a small circle girdle of c-axes due to the symmetry of elastic properties [89]. A weak $\{10 \overline{1} 1\}$ maximum perpendicular to the foliation $(\mathrm{Z})$ is actually observed in many Triassic samples (Figure 7).

Another approach to model the evolution of recrystallization textures is with polycrystal plasticity theory. In metals it is observed that recrystallization is a balance of nucleation and growth. Depending on conditions more highly deformed grains (high strain energy) are consumed by relatively undeformed neighbors (low strain energy) or strain-free nuclei form in highly deformed grains and preferentially consume host grains $[137,138]$. Such a model was successfully applied to halite, ice, quartz [139], and olivine [140]. For quartz deformed in plane strain/pure shear initially, during deformation, a Type A texture develops and expands into a girdle (Type B) [139]. The most highly deformed grains are near $Y$ and, if they develop nuclei which grow, a Y texture (Type D) develops as observed in many mylonites, mentioned earlier.

\subsection{Mechanical Dauphiné Twinning}

One aspect that we have not discussed so far is mechanical Dauphiné twinning. Mechanical twinning in quartz was first observed in compression tests of single crystals [102] and explored in some detail in the context of use of quartz as piezoelectric material [141]. Dauphiné twins are related to the host by a $180^{\circ}$ rotation (or $60^{\circ}$ taking into account the trigonal symmetry) about the c-axis [0001]. Mechanical twinning causes a microscopic distortion of the lattice without significant macroscopic

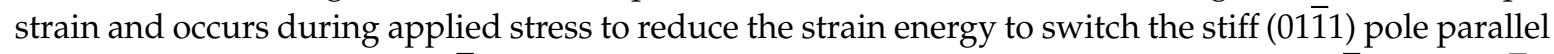
to compression to the soft (1011) pole, without changing the orientation of the c-axis, $\{10 \overline{1} 0\}$ and $\{11 \overline{2} 0\}$ orientations. In polycrystalline aggregates twins form rather easily at moderate stresses $[20,142,143]$ and twin boundaries propagate through crystals [144].

How can the orientation of rhombohedral planes in pole figures be interpreted as due to twinning or due to plastic deformation on rhombohedral slip systems? Since orientations of c-axes and a-axes are not affected by Dauphiné twins, if those lattice directions show preferred orientations, it must be attributed to other mechanisms such as basal, prismatic, and rhombohedral slip. It is likely that some twinning occurs at conditions of tectonic deformation [145-147]. Twinning is likely to occur at the initial stage of deformation or be caused at a later stages due to changing deformation geometry. In the microstructure an untwinned grain may have never been twinned or is completely twinned. There is no easy way to distinguish between the two. Also, once a grain is twinned, twinning can not accommodate further deformation and other mechanisms have to become active. The actual macroscopic strains accommodated by twinning in quartz are minimal, compared to mechanical twinning in calcite.

There is not much experimental work on rhombohedral slip mechanisms in quartz single crystals, even though, structurally they seem important. One reason is that rhombohedral orientations are easily modified by twinning. Also, the poles of equivalent unit rhombs are more or less at right angles. If one pole is parallel to the compression direction, there are two poles that are perpendicular to it. However, for interpretations of quartz deformation mechanisms it appears important to conduct such experiments and identify slip systems with transmission electron microscopy.

We have looked at Dauphine twin boundaries in the microstructure with EBSD and identified twin boundaries (yellow lines in Figure 11). These are boundaries between grains that have identical c-axes (same Euler angles $\varphi_{1}$ and $\Phi$ ) and a difference in Euler angles $\varphi_{2}$ of $60^{\circ}$. Such boundaries do indeed exist, though they are not very abundant. Table 2 (and more details in Table S2) quantifies some aspects of Dauphiné twins based on evaluations of EBSD data with program Maptex in BEARTEX [54]. Misorientations between each measured pixel and neighboring pixels were identified and if they 
correspond to Dauphiné twins plotted on the maps and statistically evaluated by comparing the total number of pixels with grain boundary pixels. These statistics include not only scans plotted in Figure 11, but all scans on the sample. Most samples have a low ratio of total twin boundary length to the probed area ranging from 0.3 to $1.5 \times 10^{-2}$. A few samples (Brg568, 981, 1135, 1137, and 1618 and Sci881) have a ratio $>2$. All of these samples are Triassic quartzites. Similar high ratios were observed for experimentally stressed quartzites [143] that we show for comparison as sample Br in Table 2C.

\subsection{Comparison of Methods of Texture Measurements}

After discussing the geological significance of these observations of quartz preferred orientation, let us look at some methodological aspects. As was mentioned earlier, a range of methods were used to investigate quartz textures, ranging from optical methods [148,149], conventional X-ray diffraction [19,65], synchrotron X-ray diffraction $[150,151]$, neutron diffraction (ranging from monochromatic [149,152] to time-of-flight [49]), and electron backscatter diffraction (EBSD) [79,143,144,146]. Results from different methods were compared $[25,49,63,149,153,154]$. Optical methods are limited to record c-axis orientations, EBSD records textures on surfaces, neutron diffraction probes large volumes of samples.

For the quartz textures described here we used TOF neutron diffraction and EBSD. We were fortunate to have had the opportunity to measure the texture of many quartzite samples with neutron diffraction at Los Alamos. As mentioned earlier we observed very consistent patterns with this technique, which assesses grain orientations over $\sim 1 \mathrm{~cm}^{3}$ samples. Even larger samples $\left(\sim 65 \mathrm{~cm}^{3}\right)$ were measured at Dubna. Such volumes provide confidence that the derived texture patterns are representative of the local rock properties at the laboratory scale. It does not imply that texture patterns are homogeneous over large areas. In fact the samples collected in the same Triassic quartz layer near Casaccia (Brg980, Brg981, and Brg1102) vary considerably over distances of $<1 \mathrm{~km}$, indicating that local heterogeneities in a geological sense can be significant. It confirms that a large number of samples is important to derive a representative interpretation.

Figure 12 compares neutron and EBSD pole figures of selected samples (a full comparison is shown in Figures S3 and S4), and Table 1 compares texture strength obtained with the two methods. The pole figures, after proper rotations of EBSD pole figures, show excellent agreement. A significant difference is that the texture strength of EBSD pole figures is consistently larger (Table 1). One explanation could be that the number of measured grains is much larger for neutrons than for EBSD, introducing statistical smoothing. Another explanation could be the angular averaging by the large neutron detectors over a considerable range (e.g., Figure 6a) [25]. With EBSD diffraction patterns crystal orientations are defined within a fraction of a degree.

This is highlighted in Figure 15 for Brg1618 from Cavi where samples cut from the same larger hand specimen were measured with neutron diffraction with HIPPO at Los Alamos (1 cm cylinders) (Figure 15a), with SKAT at Dubna (5 cm diameter spheres) (Figure 15b) and SEM-EBSD, scanning over a mm-sized surface (Figures 11 and 15c). The texture is relatively weak and the average grain size is about $0.2 \mathrm{~mm}$ (Figures 3 and 5). The two neutron diffraction measurements show excellent agreement. EBSD has a similar pattern but is less quantitative.

An advantage of EBSD is that the microstructure, including twin boundaries can be quantified (Table 2). Thus it looks like for relatively fine-grained samples, which can easily be polished and are analyzed at ambient conditions, texture analysis with EBSD is advantageous, especially with advances in detector technology that allows to collect 1000 diffraction images per second. EBSD requires much less preparation and data processing than neutron TOF texture analysis, which relies on convincing proposals with advanced planning and the rather strenuous data analysis to arrive at quantitative texture information. 


\section{Brg1618}
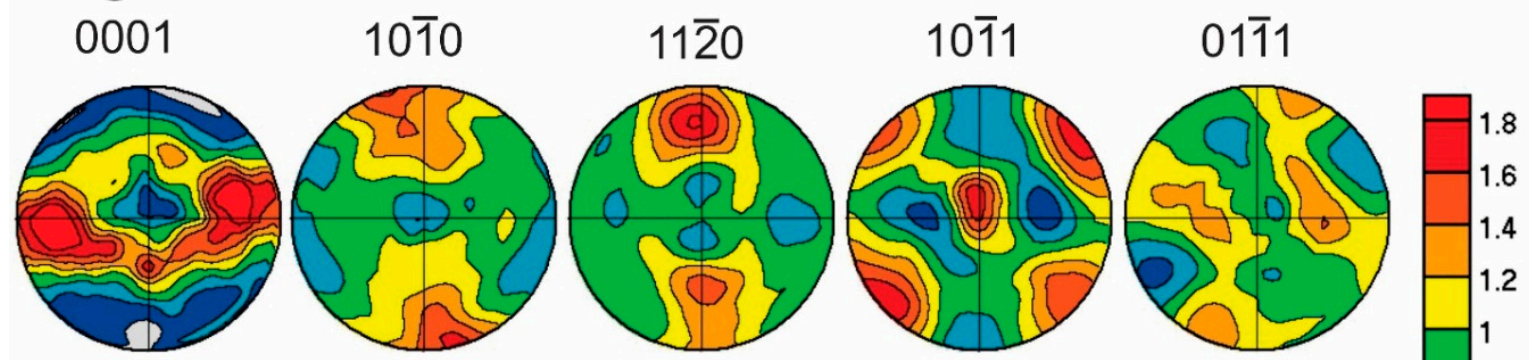

(a) HIPPO
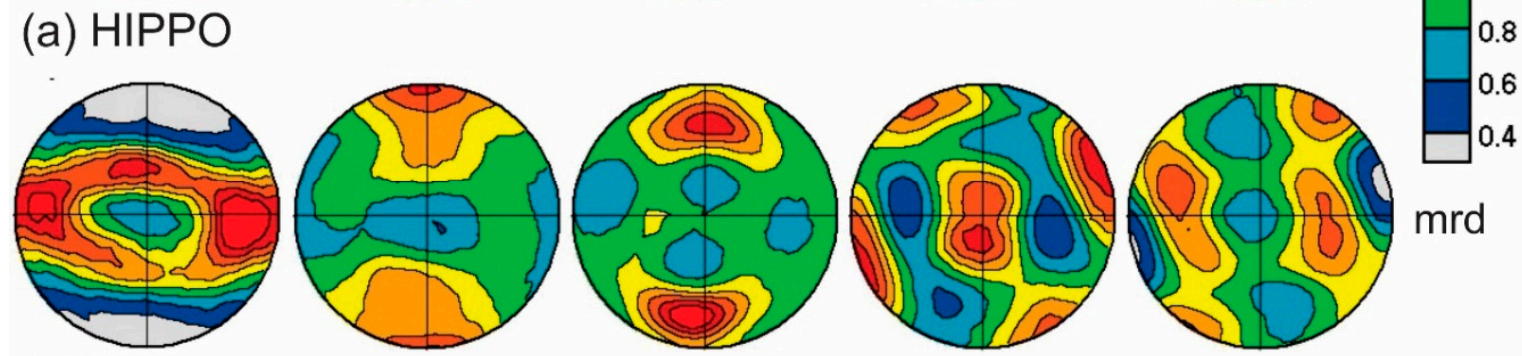

(b) Dubna
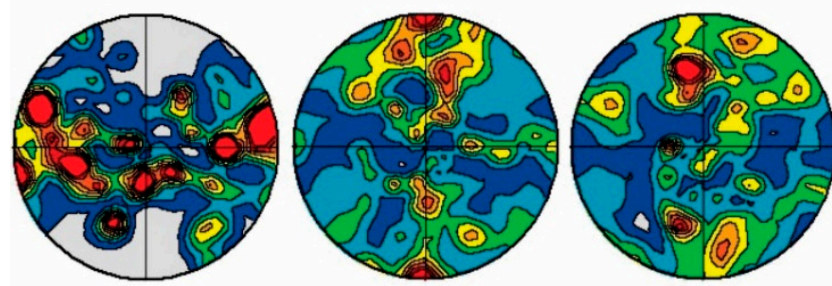

(c) EBSD
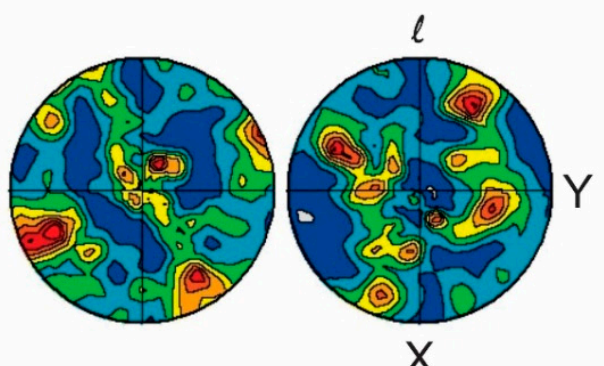

Figure 15. Comparison of neutron and EBSD pole figures for sample Brg1618. (a) Neutron diffraction with HIPPO, LAN; (b) neutron diffraction with SKAT, JINR-Dubna; and (c) EBSD with SEM. Equal area projection.

\section{Conclusions}

Preferred orientations of 24 Triassic quartzites, eight Triassic marbles, and 15 quartz layers in metamorphic gneiss from the Bergell Alps in SE Switzerland were analyzed with neutron diffraction and EBSD. Texture patterns were reciprocated with polycrystal plasticity modeling to explore likely deformation mechanisms. In Triassic quartzites from the Pennine nappes (Tambo, Suretta, Avers and Platta) and the lower Austroalpne Margna nappe quartz shows a (0001) maximum near the pole to the foliation $\mathrm{Z}$, sometimes divided into submaxima, or a $\mathrm{YZ}$ crossed girdle perpendicular to the lineation $\mathrm{X}$. A simple (0001) maximum is particularly common in quartzites of the lowest metamorphic grade (higher nappes, Avers and Magna). Also, many samples show a submaximum of $\{10 \overline{1} 1\}$ poles near $Z$. This is attributed to dominant basal $(0001)<11 \overline{2} 0>$ and rhombohedral $\{10 \overline{1} 1\}<\overline{1} 2 \overline{1} 0>$ slip accompanied by recrystallization. The texture patterns are consistent over a wide area and variations can be attributed to local changes in strain geometry. Some Triassic quartzites display deformation lamellae and EBSD maps display significant Dauphiné twin boundaries. Overall textures are moderate in strength, which may be due to presence of strongly aligned muscovite that shields stress and hinders dislocation and grain boundary movements or it could be caused by adjacent Triassic marbles that may have accommodated a significant portion of strain. Textures in quartz layers are generally very strong, with a (0001) maximum near $Y$ as has been documented in mylonites from many localities. Also here there is a $\{10 \overline{1} 1\}$ maximum near Z. Polycrystal plasticity models suggest that the Y-maximum texture is due to dominant prismatic $\{10 \overline{1} 0\}<\overline{1} 2 \overline{1} 0>$ slip combined with rhombohedral slip $\{10 \overline{1} 1\}<\overline{1} 2 \overline{1} 0>$ and dynamic recrystallization. These Y-maximum textures are particularly pronounced in mylonitic layers close to the Teriary Bergell granite contact in high amphibolite-granulite facies metamorphic conditions. Most likely is that plane strain dominates in most samples, with different fractions of pure shear 
and simple shear. There is excellent qualitative agreement between neutron diffraction pole figures and EBSD pole figures. The study suggests that rhombohedral slip may be significant in quartz and this should be approached with future deformation experiments and electron microscope studies to identify dislocations.

Supplementary Materials: The following are available online at http://www.mdpi.com/2075-163X/9/5/277/s1, This section contains two tables and four figures that display details and may be of interest to some readers. Table S1: List of additional Triassic quartzite samples with location, Swiss coordinates, and (0001) pole figure maxima (in multiples of a random distribution). These samples are not referred to in the text but pole figures determined from neutron diffraction data are shown in Figure S3; Table S2: EBSD twin boundary statistics with individual scans (Compare with Table 2 in main paper); Figure S1: Optical images of microstructures of Triassic quartzites listed in Table 1. Crossed polarizers. Scale bar is indicated on top right; Figure S2: Optical images of quartz layers listed in Table 1. Crossed polarizers. Scale bar is indicated on top right; Figure S3: Neutron diffraction pole figures of samples not included in the main text. Approximate localities are indicated under sample numbers. Equal area projection on the schistosity plane. Lineation is $l$. Numbers on top right of pole figures indicate which pole density scale was used (in mrd); Figure S4a,b: Comparison of (0001) and (10111) pole figures of quartz for Triassic quartzites and EBSD and neutron diffraction. Selected cases are also shown in Figure 12. Equal area projection on the schistosity plane. Lineation is $l$. Numbers on top right of pole figures indicate which pole density scale was used (in mrd); Figure S5: Comparison of (0001) and (1011) pole figures of quartz for quartz layers and EBSD and neutron diffraction. Selected cases are also shown in Figure 12. Equal area projection on the schistosity plane. Lineation is $l$. Numbers on top right of pole figures indicate which pole density scale was used (in $\mathrm{mrd}$ ).

Author Contributions: All authors participated in the preparation of this manuscript. H.-R.W. conducted sample collection, collaborated in HIPPO and EBSD experiments, data anaslysis and prepared the first version of the manuscript. R.Y. worked on EBSD experiments, data analysis. S.V. worked on HIPPO experiments and R.V. on SKAT experiments.

Funding: H.-R.W. is greatful for support from NSF (EAR 1343908) and DOE-BES (DE-FG02-05ER15637), R.Y. acknowledges support from IKSTP, Shaanxi, China (No.2015GY101).

Acknowledgments: We are appreciative for access to the HIPPO neutron diffraction facilities at LANSCE where most of the diffraction experiments were conducted. The user program at LANSCE was supported by DOE-BES. We also acknowledge the access to the SKAT diffractometer at JINR, Dubna. Comments from five enthusiastic reviewers were very helpful. For such a long manuscript, with over 150 references and only numbers in the text, it must have been a difficult task. We also thank T. Teague (Berkeley) for help with sample preparation, L. Morales (ETH) and C. Tomé (LANL) for discussions, particularly polycrystal plasticity modeling.

Conflicts of Interest: The authors declare no conflict of interest.

\section{References}

1. Schmidt, W. Gefügestatistik. Tschermaks Mineral. Petrog. Mitt. 1925, 38, 392-423.

2. Sander, B. Einführung in die Gefügekunde der geologischen Körper. Teil II: Die Korngefüge; Springer: Wien, Austria, 1950; p. 412. [CrossRef]

3. Behr, H.-J. Beiträge zur petrographischen und tektonischen Analyse des sächsischen Grundgebirges. Freiberger Forsch. 1961, C119, 1-118.

4. Behr, H.-J. Die Korngefügefazies der Zweigürteltektonite im kristallinen Grundgebirge Sachsens. Abh. Deutsch. Akad. Wiss. Berlin, Kl. Bergbau 1964, 1, 1-46.

5. Behr, H.-J. Zur Methodik tektonischer Forschung im kristallinen Grundgebirge. Ber. Geol. Ges. DDR. 1965, 10/2, 163-179.

6. Lister, G.S.; Dornsiepen, U.F. Fabric transition in the Saxony granulite terrain. J. Struct. Geol. 1982, 4, 81-92. [CrossRef]

7. Christie, J.M. The Moine thrust zone in the Assynt region, northwest Scotland. Calif. Univ. Publ. Geol. Sci. 1963, 40, 345-440.

8. Law, R.D. Heterogeneous deformation and quartz crystallographic fabric transitions: natural examples from the Moine Thrust zone at the stack of Glencoul, northern Assynt. J. Struct. Geol. 1987, 9, 819-833. [CrossRef]

9. Law, R.D.; Schmid, S.M.; Wheeler, J. Simple shear deformation and quartz crystallographic fabrics: A possible natural example from the Torrion area of NW Scotland. J. Struct. Geol. 1990, 12, 29-45. [CrossRef]

10. Bell, T.H.; Etheridge, M.A. The deformation and recrystallization of quartz in a mylonite zone, Central Australia. Tectonophysics 1976, 32, 235-267. [CrossRef] 
11. Wenk, H.-R. Gefügestudie an Quarzknauern und linsen der Tessiner Kulmination. Schweiz. Mineral. Petrog. Mitt. 1965, 45, 468-516.

12. Simpson, C. Oblique girdle orientation patterns of quartz c-axes from a shear zone in the basement core of the Maggia Nappe Ticino, Switzerland. J. Struct. Geol. 1980, 2, 243-247. [CrossRef]

13. Mancktelow, N.S. Quartz textures form the Simplon Fault Zone, southwest Switzerland and north Italy. Tectonophysics 1987, 135, 133-153. [CrossRef]

14. Mancktelow, N.S. Atypical textures in quartz from the Simplon fault zone. J. Struct. Geol. 1987, 9/8, 995-1005. [CrossRef]

15. Parsons, A.J.; Law, R.D.; Lloyd, R.D.; Phillips, R.J.; Searle, M.P. Thermo-kinematic evolution of the Annapurna-Dhaulagiri Himalaya, central Nepal: The composite orogenic system. Geochem. Geophys. Geosystems 2016, 17, 1511-1539. [CrossRef]

16. Long, S.P.; Gordon, S.M.; Young, J.P.; Soignard, E. Temperature and strain gradients through Lesser Himalayan rocks and across the Main Central thrust, south central Bhutan: Implications for transport-parallel stretching and inverted metamorphism. Tectonics 2016, 35, 1863-1891. [CrossRef]

17. Hunter, N.J.R.; Weinberg, R.F.; Wilson, C.J.L.; Luzin, V.; Misra, S. Microscopic anatomy of a "hot-on-cold" shear zone: Insights from quartzites from the Main Central Thrust in the Alaknanda Valley (Garhwal Himalaya). Geol. Soc. America Bull. 2018, 130, 1519-1539. [CrossRef]

18. Larson, K.P. Refining the structural framework of the Khimti Khola region, east-central Nepal Himalaya, using quartz textures and c-axis fabrics. J. Struct. Geol. 2018, 107, 142-152. [CrossRef]

19. Wenk, H.-R.; Baker, D.W.; Griggs, E.T. X-ray fabric analysis of hot-worked and annealed flint. Science 1967, 157, 1447-1449. [CrossRef]

20. Tullis, J. Quartz: Preferred orientation in rocks produced by Dauphiné twinning. Science 1970, 168, 1342-1344. [CrossRef]

21. Baker, D.W.; Wenk, H.-R.; Christie, J.M. X-ray analysis of preferred orientation in fine-grained quartz aggregates. J. Geol. 1969, 77, 144-172. [CrossRef]

22. Baker, D.W.; Wenk, H.-R. Preferred orientation in a low symmetry quartz mylonite. J. Geol. 1972, 80, 81-105. [CrossRef]

23. Dingley, D.J. A comparison of diffraction techniques for the SEM. Scanning Electr. Microsc. 1981, 4, $273-286$.

24. Kunze, K.; Adams, B.L.; Heidelbach, F.; Wenk, H.-R. Local microstructural investigations in recrystallized quartzite using orientation imaging microscopy. Mater. Sci. Forum. 1994, 157-162, 1243-1250. [CrossRef]

25. Wenk, H.-R.; Lutterotti, L.; Vogel, S.C. Rietveld texture analysis from TOF neutron diffraction data. Powder Diffr. 2010, 25, 283-296. [CrossRef]

26. Bunge, H.-J. Zur Darstellung allgemeiner Texturen. Z. Metallk. 1965, 56, 872-874.

27. Roe, R.-J. Description of crystallite orientation in polycrystalline materials III, general solution to pole figure inversion. J. Appl. Phys. 1965, 36, 2024-2031. [CrossRef]

28. Matthies, S. On the reproducibility of the orientation distribution function of texture samples from pole figures (ghost phenomena). Phys. Status Solidi B. 1979, 92, K135-K138. [CrossRef]

29. Matthies, S.; Vinel, G.W. On the reproduction of the orientation distribution function of textured samples from reduced pole figures using the concept of conditional ghost correction. Phys. Status Solidi B 1982, 112, K111-K114. [CrossRef]

30. Pawlik, K. Determination of the orientation distribution function from pole figures in arbitrarily defined cells. Phys. Status Solidi B 1986, 134, 477-483. [CrossRef]

31. Schaeben, H. Entropy optimization in texture goniometry. Phys. Status Solidi B 1988, 148, 63-72. [CrossRef]

32. Hielscher, R.; Schaeben, H. A novel pole figure inversion method: specification of the MTEX algorithm. J. Appl. Cryst. 2008, 41, 1024-1037. [CrossRef]

33. Christie, J.M.; Griggs, D.T.; Carter, N.L. Experimental evidence of basal slip in quartz. J. Geol. 1964, 72, 734-756. [CrossRef]

34. Hobbs, B.E.; McLaren, A.C.; Paterson, M.S. Plasticity of single crystals of synthetic quartz. Flow Fract. Rocks 1972, 16, 29-53. [CrossRef]

35. Baeta, R.D.; Ashbee, K.G.H. Mechanical deformation of quartz: I Constant strain-rate compression experiments. Phil. Mag. 1970, 22, 601-623. [CrossRef]

36. D'Omalius d'Halloy, J.J. Introduction a la Géologie; Levrault: Paris, France, 1833. 
37. Kurz, W.; Neubauer, F.; Genser, J.; Dachs, E. Alpine geodynamic evolution of passive and active continental margin sequences in the Tauern Window (eastern Alps, Austria, Italy): A review. Geol. Rundschau. 1998, 87, 225-242. [CrossRef]

38. Schmid, S.M.; Scharf, A.; Handy, M.R.; Rosenberg, C.L. The Tauern Window (Eastern Alps, Austria): A new tectonic map, with cross-sections and a tectonometamorphic synthesis. Swiss J. Geosci. 2013, 106, 1-32. [CrossRef]

39. Trommsdorff, V.; Montrasio, A.; Hermann, J.; Müntener, O.; Spillmann, P.; Gieré, R. The geological map of Valmalenco. Schweiz. Mineral. Petrog. Mitt. 2005, 85, 1-13.

40. Wenk, H.-R. The structure of the Bergell Alps. Eclogae Geol. Helv. 1973, 66, 255-291.

41. Wenk, H.-R.; Wenk, E.; Wallace, J. Metamorphic mineral assemblages in pelitic rocks of the Bergell Alps. Schweiz. Mineral. Petrog. Mitt. 1974, 54, 507-554.

42. Law, R.D. Crystallographic fabrics: A selective review of their applications to research in structural geology. Geol. Soc. London, Spec. Publ. 1990, 54, 335-352. [CrossRef]

43. Bishop, J.R. Piezoelectric effects in quartz-rich rocks. Tectonophysics 1981, 77, 97-321. [CrossRef]

44. Ivankina, T.I.; Nikitin, A.N.; Voitus, W.; Walther, K. Texture analysis and investigation of piezoelectric properties of natural quartz. Textures Microstruct. 1991, 14-18, 421-429. [CrossRef]

45. Frondel, C. Characters of quartz fibers. Am. Mineral. 1978, 63, 17-27.

46. Tanaka, Y.; Kojima, T.; Takata, Y.; Chainani, A.; Lovesey, S.W.; Knight, K.S.; Takeuchi, T.; Oura, M.; Senba, Y.; Ohashi, H.; et al. Determination of structural chirality of berlinite and quartz using resonant $X$-ray diffraction with circularly polarized X-rays. Physic. Rev. B 2010, 81, 144104. [CrossRef]

47. Matthies, S.; Wenk, H.-R.; Vinel, G.W. Some basic concepts of texture analysis and comparison of three methods to calculate orientation distributions from pole figures. J. Appl. Crystallogr. 1988, 21, 285-304. [CrossRef]

48. Pehl, J.; Wenk, H.-R. Evidence for regional Dauphiné twinning in quartz from the Santa Rosa mylonite zone in Southern California. A neutron diffraction study. J. Struct. Geol. 2005, 27, 1741-1749. [CrossRef]

49. Wenk, H.-R.; Lutterotti, L.; Vogel, S.C. Texture analysis with the new HIPPO TOF diffractometer. Nucl. Instr. Methods A. 2003, 515, 575-588. [CrossRef]

50. Ullemeyer, K.; Spalthoff, P.; Heinitz, J.; Isakov, N.N.; Nikitin, A.N.; Weber, K. The SKAT texture diffractometer at the pulsed reactor IBR-2 at Dubna: Experimental layout and first measurements. Nucl. Instr. Methods A. 1998, 412, 80-88. [CrossRef]

51. Keppler, R.; Ullemeyer, K.; Behrmann, J.H.; Stipp, M. Potential of full pattern fit methods for the texture analysis of geological materials: Implications from texture measurements at the recently upgraded neutron time-of-flight diffractometer SKAT. J. Appl. Crystallogr. 2014, 47, 1520-1534. [CrossRef]

52. Lutterotti, L.; Matthies, S.; Wenk, H.-R.; Schultz, A.J.; Richardson, J.W. Combined texture and structure analysis of deformed limestone from time-of-flight neutron diffraction spectra. J. Appl. Phys. 1997, 81, 594-600. [CrossRef]

53. Kihara, K. An X-ray study of the temperature dependence of the quartz structure. Eur. J. Mineral. 1990, 2/1, 63-77. [CrossRef]

54. Wenk, H.-R.; Matthies, S.; Donovan, J.; Chateigner, D. BEARTEX: A Windows-based program system for quantitative texture analysis. J. Appl. Crystallogr. 1998, 31, 262-269. [CrossRef]

55. Matthies, S.; Wenk, H.-R. Transformations for monoclinic crystal symmetry in texture analysis. J. Appl. Cryst. 2009, 42, 564-571. [CrossRef]

56. Tullis, J.; Christie, J.M.; Griggs, D.T. Microstructures and preferred orientations of experimentally deformed quartzites. Geol. Soc. Am. Bull. 1973, 84, 297-314. [CrossRef]

57. Stipp, M.; Kunze, K. Dynamic recrystallization near the brittle-plastic transition in naturally and experimentally deformed quartz aggregates. Tectonophysics 2008, 448, 77-97. [CrossRef]

58. Tullis, J. Preferred orientation of quartz produced by slip during plane strain. Tectonophysics 1977, 39, 87-102. [CrossRef]

59. Dell'Angelo, L.N.; Tullis, J. Fabric development in experimentally sheared quartzites. Tectonophysics 1989, 169, 1-21. [CrossRef]

60. Mainprice, D.H.; Bouches, J.L.; Blumenfeld, P.; Tubiá, J.M. Dominant c slip in naturally deformed quartz: Implications for dramatic plastic softening at high temperature. Geology 1986, 14, 819-822. [CrossRef] 
61. Toy, V.G.; Prior, D.J.; Norris, R.J. Quartz fabrics in the Alpine Fault mylonites: Influence of pre-existing preferred orientations on fabric development during progressive uplift. J. Struct. Geol. 2008, 30, 602-621. [CrossRef]

62. Trommsdorff, V.; Wenk, E. Diskussion eines Zwillingsgefüges durch Achsenverteilungsanalyse an Quarz eines Tessiner Gneisses. Schweiz. Mineral. Petrog. Mitt. 1963, 43, 687-698.

63. Fazio, E.; Punturo, R.; Cirrincione, R.; Kern, H.; Pezzino, A.; Wenk, H.-R.; Goswami, S.; Mamtani, M.A. Quartz preferred orientation in naturally deformed mylonitic rocks (Montalto Shear Zone-Italy): A comparison of results by different techniques, their advantages and limitations. Int. J. Earth Sci. 2017, 106, 2259-2278. [CrossRef]

64. Wilson, C.J.L. Preferred orientation in quartz ribbon mylonites. Geol. Soc. Am. Bull. 1975, 86, 968-974. [CrossRef]

65. Schmid, S.M.; Casey, M.; Starkey, J. An illustration of the advantages of a complete texture analysis described by the orientation distribution function (ODF) using quartz pole figure data. Tectonophysics 1981, 78, 101-117. [CrossRef]

66. Carreras, J.; Estrada, A.; White, S. The effects of folding on the c-axis fabrics of a quartz mylonite. Tectonophysics 1977, 39, 3-24. [CrossRef]

67. Okudaira, T.; Takeshita, T.; Hara, I.; Ando, J. A new estimate of the conditions for transition from basal <a $>$ to prism [c] slip in naturally deformed quartz. Tectonophysics 1995, 250, 31-46. [CrossRef]

68. Barth, N.C.; Hacker, B.R.; Seward, G.G.E.; Walsh, E.O.; Young, D.; Johnston, S. Strain within the ultrahigh-pressure Western Gneiss region of Norway recorded by quartz CPOs. Geol. Soc. London Spec. Publ. 2010, 335, 663-685. [CrossRef]

69. Knipe, R.J.; Law, R.D. The influence of crystallographic orientation and grain boundary migration on microstructural and textural evolution in an S-C mylonite. Tectonophysics 1987, 135, 155-169. [CrossRef]

70. Law, R.D.; Mainprice, D.; Casey, M.; Lloyd, G.E.; Knipe, R.J.; Cook, B.; Thigpen, J.R. Moine thrust zone mylonites at the Stack of Glencoul: I-Microstructures, strain and influence of recrystallization on quartz crystal fabric development. Geol. Soc. London Spec. Publ. 2010, 335, 543-577. [CrossRef]

71. Pennacchioni, G.; Menegon, L.; Leiss, B.; Nestola, F.; Bromiley, G. Development of crystallographic preferred orientation and microstructure during plastic deformation of natural coarse-grained quartz veins. J. Geophys. Res. 2010, 115, B12405. [CrossRef]

72. Stipp, M.; Stünitz, H.; Heilbronner, R.; Schmid, S.M. The Eastern Tonale fault zone: A "natural laboratory" for crystal plastic deformation of quartz over a temperature range from $250{ }^{\circ} \mathrm{C}$ to $700{ }^{\circ} \mathrm{C}$. J. Struct. Geol. 2002, 24, 1861-1884. [CrossRef]

73. Hara, I.; Takeda, K.; Kimura, T. Preferred lattice orientation of quartz in shear deformation. J. Sci. Hiroshima Univ. Ser. C 1973, 7, 1-11.

74. Bouchez, J.L.; Pecher, A. Plasticité du quartz et sens de cisaillement dans les quartzites du grand Chevauchement Central Himalayen. Bull. Soc. Geol. Fr. 1976, 6, 1377-1384. [CrossRef]

75. Lister, G.S. Discussion. Cross-girdle c-axis fabrics in quartzites plastically deformed by plane strain and progressive simple shear. Tectonophysics 1977, 39, 51-54. [CrossRef]

76. Brunel, M. Quartz fabrics in shear-zone mylonites: Evidence for a major imprint due to late strain increments. Tectonophysics 1980, 64, T33-T44. [CrossRef]

77. Lloyd, G.E.; Freeman, B. Dynamic recrystallization of quartz under greenschist conditions. J. Struct. Geol. 1994, 16, 867-881. [CrossRef]

78. Takeshita, T.; Wenk, H.-R.; Lebensohn, R. Development of preferred orientation and microstructure in sheared quartzite: Comparison of natural and simulated data. Tectonophysics 1999, 312, 133-155. [CrossRef]

79. Heidelbach, F.; Kunze, K.; Wenk, H.-R. Texture nalysis of a recrystallized quartzite using electron diffraction in the scanning electron microscope. J. Struct. Geol. 2000, 22, 91-104. [CrossRef]

80. Keller, L.M.; Stipp, M. The single slip hypothesis revisited: Crystal-preferred orientations of sheared quartz aggregates with increasing strain in nature and numerical simulation. J. Struct. Geol. 2011, 33, 1491-1500. [CrossRef]

81. Kilian, R.; Heilbronner, R.; Stünitz, H. Quartz microstructures and crystallographic preferred orientation: Which shear sense do they indicate? J. Struct. Geol. 2011, 33, 1446-1466. [CrossRef] 
82. Morales, L.F.G.; Mainprice, D.; Lloyd, G.E.; Law, R.D. Crystal fabric development and slip systems in a quartz mylonite: An approach via transmission electron microscopy and viscoplastic self-consistent modelling. Geol. Soc. London Special Publ. 2011, 360, 151-174. [CrossRef]

83. Lister, G.S.; Williams, P.F. Fabric development in shear zones: theoretical controls and observed phenomena. J. Struct. Geol. 1979, 1, 283-297. [CrossRef]

84. Heilbronner, R.; Tullis, J. Evolution of c-axis pole figures and grain size during dynamic recrystallization: Results from experimentally sheared quartzite. J. Geophys. Res. 2006, 111, B10202. [CrossRef]

85. Kilian, R.; Heilbronner, R. Analysis of crystallographic preferred orientation of experimentally deformed Black Hills quartzite. Solid Earth 2017, 8, 1095-1117. [CrossRef]

86. Lister, G.S.; Paterson, M.S. The simulation of fabric development during plastic deformation and its application to quartzite: Fabric transitions. J. Struct. Geol. 1979, 1, 99-115. [CrossRef]

87. Lister, G.S.; Hobbs, B.E. The simulation of fabric development during plastic deformation and its application to quartzite: The influence of deformation history. J. Struct. Geol. 1980, 2, 355-370. [CrossRef]

88. Morales, L.F.G.; Lloyd, G.E.; Mainprice, D. Fabric transitions in quartz via viscoplastic self-consistent modeling part I: Axial compression and simple shear under constant strain. Tectonophysics 2014, 636, 52-69. [CrossRef]

89. Heyliger, P.; Ledbetter, H.; Kim, S. Elastic constants of natural quartz. J. Acoust. Soc. Am. 2003, 114, 644-650. [CrossRef]

90. Carter, N.L. Basal quartz deformation lamellae; a criterion for recognition of impactites. Am. J. Sci. 1965, 263, 786-806. [CrossRef]

91. Christie, J.M.; Raleigh, C.B. The origin of deformation lamellae in quartz. Am. J. Sci. 1959, 257, $385-407$. [CrossRef]

92. McLaren, A.C.; Turner, R.G.; Boland, J.N.; Hobbs, B.E. Dislocation structure of the deformation lamellae in synthetic quartz; a study by electron and optical microscopy. Contrib. Mineral. Petrol. 1970, 29, 104-115. [CrossRef]

93. White, S. Geological significance of recovery and recrystallization processes in quartz. Tectonophysics 1977, 39, 143-170. [CrossRef]

94. Christie, J.M.; Ardell, A.J. Substructures of deformation lamellae in quartz. Geology 1974, 2, 405-408. [CrossRef]

95. Vernooij, M.G.C.; Langenhorst, F. Experimental reproduction of tectonic deformation lamellae in quartz and comparison to shock-induced planar deformation features. Meteor. Planet. Sci. 2005, 40, 1353-1361. [CrossRef]

96. Trepman, C.A.; Spray, J.G. Planar microstructures and Dauphiné twins in shocked quartz from the Charlevoix impact structure, Canada. Geol. Soc. Amer. Special Paper 2005, 384, 315-328. [CrossRef]

97. Gratz, A.J.; Tyburczy, J.; Christie, J.; Ahrens, T.; Pongratz, P. Shock metamorphism of deformed quartz. Phys. Chem. Miner. 1988, 16, 221-233. [CrossRef]

98. Gratz, A.J.; Nellis, W.J.; Christie, J.M.; Brocious, W.; Swegle, J.; Cordier, P. Shock metamorphism of quartz with initial temperatures -170 to $+1000{ }^{\circ} \mathrm{C}$. Phys. Chem. Miner. 1992, 19, 267-288. [CrossRef]

99. Stöffler, D.; Langenhorst, F. Shock metamorphism of quartz in nature and experiment: I. Basic observation and theory. Meteoritics 1994, 29, 155-181. [CrossRef]

100. French, B.M.; Koeberl, C. The convincing identification of terrestrial meteorite impact structures: What works, what doesn't, and why. Earth-Sci. Rev. 2010, 98, 123-170. [CrossRef]

101. Hamers, M.F.; Pennock, G.M.; Herwegh, M.; Drury, M.R. Distinction between amorphous and healed planar deformation features in shocked quartz using composite color scanning electron microscope cathodoluminescence (SEM-CL) imaging. Meteorit. Planet. Sci. 2016, 51, 1914-1931. [CrossRef]

102. Schubnikow, A. Über Schlagfiguren des Quarzes. Z. Kristallogr. 1930, 74, 103-104.

103. Molinari, A.; Canova, G.; Ahzi, S. A self consistent approach of the large deformation polycrystal viscoplasticity. Acta Metall. 1987, 35, 2983-2994. [CrossRef]

104. Lebensohn, R.; Tomé, C.A. self-consistent visco-plastic model: Prediction of rolling textures of anisotropic materials. Mater. Sci. Eng. A 1994, 175, 71-82. [CrossRef]

105. Wenk, H.-R.; Canova, G.; Molinari, A.; Kocks, U.F. Viscoplastic modeling of texture development in quartzite. J. Geophys. Res. 1989, 94, 17895-17906. [CrossRef] 
106. Wenk, H.R. Deformation of mylonites in Palm Canyon, California, based on xenolith geometry. J. Struct. Geol. 1998, 20, 559-571. [CrossRef]

107. Song, W.J.; Ree, J.H. Effect of mica on the grain size of dynamically recrystallized quartz in a quartz-muscovite mylonite. J. Struct. Geol. 2007, 29, 1872-1881. [CrossRef]

108. Ebert, A.; Herwegh, M.; Evans, B.; Pfiffner, A.; Austin, N.; Vennemann, T. Microfabrics in carbonate mylonites along a large-scale shear zone (Helvetic Alps). Tectonophysics 2007, 444, 1-26. [CrossRef]

109. Herwegh, M.; Linckens, J.; Ebert, A.; Berger, A.; Brodhag, S.H. The role of second phases for controlling microstructural evolution in polymineralic rocks: A review. J. Struct. Geol. 2011, 33, 1728-1750. [CrossRef]

110. Tullis, J.; Wenk, H.-R. Effect of muscovite on the strength and lattice preferred orientations of experimentally deformed quartz aggregates. Mater. Sci. Eng. A 1994, 175, 209-220. [CrossRef]

111. Canova, G.R.; Wenk, H.-R.; Molinari, A. Deformation modeling of multiphase polycrystals: Case of a quartz-mica aggregate. Acta Metall. Mater. 1992, 40, 1519-1530. [CrossRef]

112. Vasin, R.; Kern, H.; Lokajicek, T.; Svitek, T.; Lehmann, E.; Mannes, D.C.; Chaouche, M.; Wenk, H.-R. Elastic anisotropy of Tambo gneiss from Promontogno, Switzerland: A comparison of crystal orientation and microstructure-based modeling and experimental measurements. Geophys. J. Int. 2017, 209, 1-20. [CrossRef]

113. Rutter, E.H. Influence of temperature, strain rate and interstitial water in experimental deformation of calcite rocks. Tectonophysics 1974, 22, 311-334. [CrossRef]

114. De Bresser, J.H.P.; Spiers, C.J. Strength characteristics of the $\mathrm{r}, \mathrm{f}$, and c slip systems in calcite. Tectonophysics 1997, 272, 1-23. [CrossRef]

115. Turner, F.J.; Griggs, D.T.; Clark, R.H.; Dixon, R.H. Deformation of Yule marble, part VII: Development of oriented fabrics at $300{ }^{\circ} \mathrm{C}-400{ }^{\circ} \mathrm{C}$. Geol. Soc. Am. Bull. 1956, 67, 1259-1294. [CrossRef]

116. Schmid, S.M.; Paterson, M.S.; Boland, J.N. High temperature flow and dynamic recrystallization in Carrara marble. Tectonophysics 1980, 65, 245-280. [CrossRef]

117. De Raadt, W.S.; Burlini, L.; Kunze, K.; Spiers, C.J. Effect of pre-existing crystallographic preferred orientation on the rheology of Carrara marble. J. Struct. Geol. 2014, 68, 44-57. [CrossRef]

118. Pieri, M.; Burlini, L.; Kunze, K.; Stretton, I.; Olgaard, D.L. Rheological and microstructural evolution of Carrara marble with high shear strain: Results from high temperature torsion experiments. J. Struct. Geol. 2001, 23, 1393-1413. [CrossRef]

119. Pieri, M.; Kunze, K.; Burlini, L.; Stretton, I.; Olgaard, D.L.; Burg, J.-P.; Wenk, H.-R. Texture development of calcite by deformation and dynamic recrystallization at $1000 \mathrm{~K}$ during torsion experiments of marble to large strains. Tectonophysics 2001, 330, 119-140. [CrossRef]

120. Trommsdorff, V. Gefügestudien an Calcitmarmor aus Val Prato (Tessin). Schweiz. Mineral. Petrog. Mitt. 1964, 44, 595-611.

121. Romeo, I.; Capote, R.; Lunar, R. Crystallographic preferred orientation and microstructure of a Variscan marble mylonite in the Ossa-Morena Zone (SW Iberia). J. Struct. Geol. 2007, 29, 1353-1368. [CrossRef]

122. Rutter, E.H.; Rusbridge, M. The effect of non-coaxial strain paths on crystallographic preferred orientation development in the experimental deformation of a marble. Tectonophysics 1977, 39, 73-86. [CrossRef]

123. Schmid, S.M.; Panozzo, R.; Bauer, S. Simple shear experiments on calcite rocks: Rheology and microfabric. J. Struct. Geol. 1987, 9, 747-778. [CrossRef]

124. Wenk, H.-R.; Takeshita, T.; Bechler, E.; Erskine, B.; Matthies, S. Pure shear and simple shear calcite textures. Comparison of experimental, theoretical and natural data. J. Struct. Geol. 1987, 9, 731-745. [CrossRef]

125. Trommsdorff, V.; Wenk, H.-R. Die Regelung des Dolomites von Crevola (Simplon), Diskussion und Probleme. Schweiz. Mineral. Petrog. Mitt. 1965, 45, 551-569.

126. Holyoke III, C.W.; Kronenberg, A.K.; Newman, J. Dislocation creep of polycrystalline dolomite. Tectonophysics 2013, 590, 72-82. [CrossRef]

127. Mainprice, D.H.; Paterson, M.S. Experimental studies of the role of water in the plasticity of quartzites. J. Geophys. Res. 1984, 89, 4257-4296. [CrossRef]

128. Stipp, M.; Tullis, J.; Scherwath, M.; Behrmann, J.H. A new perspective on paleopiezometry: Dynamically recrystallized grain size distributions indicate mechanism changes. Geology 2010, 38, 759-762. [CrossRef]

129. Cross, A.J.; Prior, D.J.; Stipp, M.; Kidder, S. The recrystallized grain size piezometer for quartz: An EBSD-based calibration. Geophys. Res. Lett. 2017, 44, 6667-6674. [CrossRef] 
130. Gleason, G.C.; Tullis, J.; Heidelbach, F. The role of dynamic recrystallization in the development of lattice preferred orientations in experimentally deformed quartz aggregates. J. Struct. Geol. 1993, 15, 1145-1168. [CrossRef]

131. Halfpenny, A.; Prior, D.J.; Wheeler, J. Electron backscatter diffraction analysis to determine the mechanisms that operated during dynamic recrystallization of quartz-rich rocks. J. Struct. Geol. 2012, 36, 2-15. [CrossRef]

132. Hirth, G.; Tullis, J. Dislocation creep regimes in quartz aggregates. J. Struct. Geol. 1992, 14, 145-159. [CrossRef]

133. Humphreys, F.J.; Hatherly, M. Recrystallization and Related Annealing Phenomena; Oxford University Press: Oxford, UK, 1995.

134. Kamb, W.B. Theory of preferred orientation developed by recrystallization under stress. J. Geol. 1959, 67, 153-170. [CrossRef]

135. Shimizu, I. Nonhydrostatic and nonequilibrium thermodynamics of deformable materials. J. Geophys. Res. 1992, 97, 4587-4597. [CrossRef]

136. Shimizu, I. Theories and applicability of grain size piezometers: The role of dynamic recrystallization mechanisms. J. Struct. Geol. 2008, 30, 899-917. [CrossRef]

137. Jessell, M.W. Simulation of fabric development in recrystallizing aggregates, I. Description of the model. J. Struct. Geol. 1988, 10, 771-778. [CrossRef]

138. Jessell, M.W. Simulation of fabric development in recrystallizing aggregates, II. Example model runs. J. Struct. Geol. 1988, 10, 779-793. [CrossRef]

139. Wenk, H.-R.; Canova, G.; Bréchet, Y.; Flandin, L. A deformation-based model for recrystallization of anisotropic materials. Acta Mater. 1997, 45, 3283-3296. [CrossRef]

140. Wenk, H.-R.; Tomé, C.N. Modeling dynamic recrystallization of olivine dynamic in simple shear. J. Geophys. Res. 1999, 104, 25513-25527. [CrossRef]

141. Thomas, L.A.; Wooster, W.A. Piezocrescence-The growth of Dauphiné twinning in quartz under stress. Proc. R. Soc. Lond. Math. Phys. Sci. 1951, A 208, 43-62. [CrossRef]

142. Tullis, J.; Tullis, T.E. Preferred orientation produced by mechanical Dauphiné twinning. Thermodynamics and axial experiments. Am. Geophys. U. Monogr. 1972, 16, 67-82. [CrossRef]

143. Minor, A.; Rybacki, E.; Sintubin, M.; Vogel, S.; Wenk, H.-R. Tracking mechanical Dauphiné twin evolution with applied stress in axial compression experiments on a low-grade metamorphic rock. J. Struct. Geol. 2018, 112, 81-94. [CrossRef]

144. Wenk, H.-R.; Barton, N.; Bortolotti, M.; Vogel, S.; Voltolini, M.; Lloyd, G.E.; Gonzalez, G.B. Dauphiné twinning and texture memory in polycrystalline quartz. Part 3: Texture memory during phase transformation. Phys. Chem. Miner. 2009, 37, 567-583. [CrossRef]

145. Menegon, L.; Pennacchioni, G.; Heilbronner, R.; Pittarello, L. Evolution of quartz microstructure and c-axis crystallographic preferred orientation within ductilely deformed granitoids (Arolla Unit, Western Alps). J. Struct. Geol. 2008, 30, 1332-1347. [CrossRef]

146. Menegon, L.; Piazolo, S.; Pennacchioni, G. The effect of Dauphiné twinning on plastic strain in quartz. Contrib. Mineral Petrol. 2011, 161, 635-652. [CrossRef]

147. Rahl, J.M.; McGrew, A.J.; Fox, J.A.; Latham, J.R.; Gabrielson, T. Rhomb-dominated crystallographic preferred orientations in incipiently deformed quartz sandstones: A potential paleostress indicator for quartz-rich rocks. Geology 2018, 46, 195-198. [CrossRef]

148. Heilbronner, R.; Pauli, C. Integrated spatial and orientation analysis of quartz c-axes by computer-aided microscopy. J. Struct. Geol. 1993, 15, 369-382. [CrossRef]

149. Hunter, N.J.R.; Wilson, C.J.L.; Luzin, V. Comparison of quartz crystallographic preferred orientations identified with optical fabric analysis, electron backscatter and neutron diffraction techniques. J. Microsc. 2017, 265, 169-184. [CrossRef]

150. Lutterotti, L.; Vasin, R.; Wenk, H.-R. Rietveld texture analysis from synchrotron diffraction images: I. Basic analysis. Powder Diffr. 2014, 29, 76-84. [CrossRef]

151. Wenk, H.-R.; Lutterotti, L.; Kaercher, P.; Kanitpanyacharoen, W.; Miyagi, L.; Vasin, R. Rietveld texture analysis from synchrotron diffraction images: II. Complex multiphase materials and diamond anvil cell experiments. Powder Diffr. 2014, 29, 220-232. [CrossRef]

152. Wenk, H.-R. Standard project for pole figure determination by neutron diffraction. J. Appl. Cryst. 1991, 24, 920-927. [CrossRef] 
153. Ullemeyer, K.; Braun, G.; Dahms, M.; Kruhl, J.H.; Olesen, N.Ø.; Siegesmund, S. Texture analysis of a muscovite-bearing quartzite: A comparison of some currently used techniques. J. Struct. Geol. 2000, 22, 1541-1557. [CrossRef]

154. Wenk, H.-R. Texture analysis by advanced diffraction methods. In Modern Diffraction Methods; Mittemeijer, E.J., Welzel, U., Eds.; Wiley-VCH: Weinheim, Germany, 2012; pp. 173-220. 